\title{
Finite Element Analysis of Large Plastic Deformation Process of Pure Molybdenum Plate During Hot Rolling
}

Ping Hu ( $\nabla$ huping1985@126.com )

School of Metallurgy Engineering, Xi'an University of Architecture and Technology, Xi'an 710055, China Quan Cheng

School of Metallurgy Engineering, Xi'an University of Architecture and Technology, Xi'an 710055, China Hai rui Xing

School of Metallurgy Engineering, Xi'an University of Architecture and Technology, Xi'an 710055, China Shi lei Li

School of Metallurgy Engineering, Xi'an University of Architecture and Technology, Xi'an 710055, China Jia yu Han

School of Metallurgy Engineering, Xi'an University of Architecture and Technology, Xi'an 710055, China

\section{Song wei Ge}

School of Metallurgy Engineering, Xi'an University of Architecture and Technology, Xi'an 710055, China

\section{Xing jiang Hua}

School of Metallurgy Engineering, Xi'an University of Architecture and Technology, Xi'an 710055, China

\section{Bo liang Hu}

School of Metallurgy Engineering, Xi'an University of Architecture and Technology, Xi'an 710055, China

\section{Kuai she Wang}

School of Metallurgy Engineering, Xi'an University of Architecture and Technology, Xi'an 710055, China Wen Zhang

Northwest Institute for Non-ferrous Metal Research, Xi'an, Shaanxi Province 710016, China

\section{Research Article}

Keywords: pure molybdenum, unidirectional hot rolling, cross hot rolling, finite element method

Posted Date: April 12th, 2021

DOI: https://doi.org/10.21203/rs.3.rs-382057/v1

License: (c) (1) This work is licensed under a Creative Commons Attribution 4.0 International License. Read Full License 
Finite element analysis of large plastic deformation process of pure molybdenum plate during

\section{hot rolling}

Ping Hu ${ }^{1,2} \cdot$ Quan Cheng ${ }^{1,2} \cdot$ Hairui Xing ${ }^{1,2} \bullet$ Shilei Li ${ }^{1,2} \bullet$ Jiayu Han ${ }^{1,2} \cdot$ Songwei Ge ${ }^{1,}$

2 Xingjiang Hua ${ }^{1,2} \cdot$ Boliang $\mathrm{Hu}^{1,2} \cdot$ Kuaishe Wang ${ }^{1,2} \cdot$ Wen Zhang ${ }^{3}$

Abstract: Rare molybdenum resources have been increasingly involved in heavy industries. In this paper, the common unidirectional and cross hot rolling operations, for pure molybdenum plate, are numerically simulated by using MSC. Marc software. An elastic-plastic finite element model is employed together with updated Lagrange method to predict stress and strain fields in the work-piece. The results showed that there was a typical three-dimensional additional compressive stress $\left(\sigma_{\mathrm{y}}>\sigma_{z}>\sigma_{\mathrm{x}}\right)$ in deformation zone, while strain could be divided into uniaxial compressive strain and biaxial tensile strain $\left(\varepsilon_{y}>\varepsilon_{\times}>\varepsilon_{z}\right)$. Tensile stress $\sigma_{\times}$increased with the accumulation of reduction and the decrease of friction coefficient at the edge of width spread. More importantly, the interlaced deformation caused by cross commutation was helpful to repair the severe anisotropy created by unidirectional hot rolling. By comparing the theoretical verification of rolling forces and the measured temperatures with the simulated values, eventually, it is demonstrated that the model is aligning well with the actual engineering.

Keywords: pure molybdenum · unidirectional hot rolling $\cdot$ cross hot rolling $\cdot$ finite element method

\section{Introduction}

$\triangle$ Ping Hu \& Kuaishe Wang huping1985@126.com (Ping Hu) \& wangkuaishe888@126.com (Kuai-she Wang)

${ }^{1}$ School of Metallurgy Engineering, Xi'an University of Architecture and Technology, Xi'an 710055, China

${ }^{2}$ National and Local Joint Engineering Research Center for Functional Materials Processing, Xi'an University of Architecture and Technology, Xi'an 710055, China

${ }^{3}$ Northwest Institute for Non-ferrous Metal Research, Xi'an, Shaanxi Province 710016, China 
Pure molybdenum (BCC) with high stacking fault energy, as a typical representative of rare and strategic refractory metal (melting point $2620{ }^{\circ} \mathrm{C}$ ), is often utilized for producing high value-added products. Because of its excellent properties of high strength and rigidity, good electrical and thermal conductivity at elevated temperatures and its strong corrosion resistance, it is extensively used in aerospace, mechanical electronics, nuclear industry and other fields [1-3]. However, molybdenum has a higher ductile to brittle transition temperature, and poor oxidation resistance at high temperatures, and there are fewer slip systems that can operate independently, which makes its manufacturing and application extremely difficult [4-5]. The conventional molybdenum products include bars, plates and wires. Among them, the most widely applied and potentially valuable is sheet metal processing, which has to be handled through rolling engineering [6]. Currently, there are two kinds of thermal deformation of molybdenum sheet: an unidirectional hot rolling (UHR) and a cross hot rolling (CHR), but a variety of defects are often accompanied by them, such as surface edge cracks and delamination [7-9]. Essentially, this is due to the serious genetic effect of passes and unreasonable control of processing parameters, the technical requirements are badly-needed.

Hot rolling is a continuous inheritance process that integrates the mutual iterative influence of temperature and force field variables. The main variables are rolling pressure, temperature, rolling speed, reduction, roll diameter, and friction coefficient. The material and geometric nonlinearity and boundary condition nonlinearity are the core and dominant factors of thermal-mechanical coupling behavior [10]. Therefore, this is a very complicated problem, and it is not easy to intuitively and rationally explore a reasonable range of molding parameters and micro-metallurgical characteristics 
through simple experimental trial-and-error. The technology of finite element analysis (FEA) as a powerful and efficient numerical simulation tool has been widely recognized in academia and industry, especially in plastic forming of rolling, and plays an irreplaceable role in the description of material flow behavior. Commercially available software packages like MSC. Marc, ABAQUS, DEFORM etc. also greatly reduce the workload of engineers. Most of the traditional mathematical models are based on the elastic-plastic and rigid-plastic ones, assuming that the strip is isotropic and homogeneous, and interface boundary conditions refer to shear or Coulomb friction model [11-12]. In the later research, various factors were taken into account more realistically, such as setting the hybrid friction factor, treating the interfacial heat transfer coefficient as a function of temperature and pressure, and exerting interface lubrication [13-14], which have greatly improved the practical value of calculation. Analytical approach of Arbitrary Lagrangian and Eulerian (ALE) was employed to enhance the previous idea of updated Lagrange [15]. In recent decades, generally speaking, 2D/3D thermo-mechanical coupling simulation has seen the application in lightweight alloys (aluminum and magnesium alloys) and steels [16-20], but the study in the field of refractory metal is still relatively small, especially the development of molybdenum sheet [21-22]. Compared with UHR, although the deformation pattern of CHR is similar to that of it, the transition of rolling direction makes the field state exchange dramatically, and the difference of mechanical properties in both vertical and horizontal orientations is also compensated apparently. However, the genetic pattern of these characteristic field quantities does not seem to be clear in the current researches [23-24], which needs further exploration and exploitation. In order to reduce the rolling scrap caused by manual experience and to increase the yield of molybdenum sheet, it is necessary to 
systematically study the formation of sheet by means of computer design and parameters optimization.

The chief assignment of this work is to carry out a numerical model for UHR and CHR of molybdenum plate, and analyze the fields of temperature, stress, strain and additional stress-strain before and after cross reversing carefully. Subsequently, the parameters related to the depth of chilling, the distribution of additional tensile/compressive stresses in width and the history of plastic strain in rolling direction on the surface of plate are discussed and designed, which will provide an important guidance for restraining the anisotropy, improving the uniformity and mechanical properties in the vertical and horizontal directions, and developing deep processing terminal products of sheet metal.

\section{Experimental details}

In this study, the slab was prepared by powder metallurgy, followed by hot rolling. The detailed process is shown in Fig. 1. Firstly, the molybdenum powder with purity greater than 99.95\% was loaded into the mold, and it was pressed into billets by cold isostatic pressing in YT79-500 hydraulic machine (the pressure was $180 \mathrm{MPa}$ ), and then sintered by solid phase staged sintering in medium frequency induction sintering furnace (the sintering temperature was $1880{ }^{\circ} \mathrm{C}$, and sintering time was up to $18.5 \mathrm{~h}$ ). Finally, the obtained sintered billets were heated to $1320{ }^{\circ} \mathrm{C}$ in a stove with hydrogen atmosphere protection for about two hours, and then moved out immediately for rolling. The rolling schedule is shown in Table 1. 


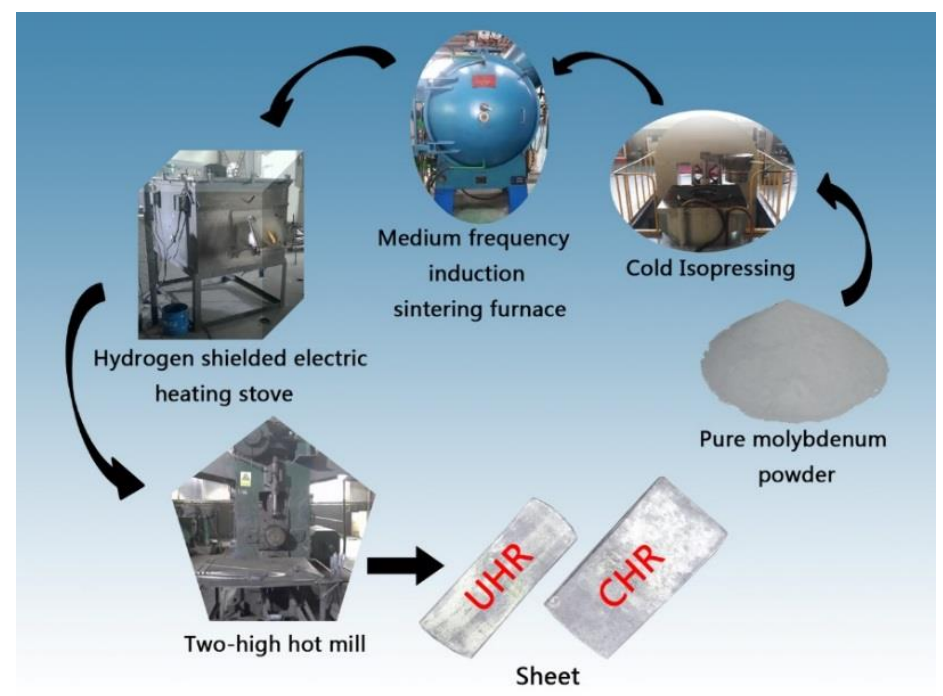

Fig. 1. Preparation and rolling of molybdenum plate.

Table 1. Rolling schedule.

\begin{tabular}{|c|c|c|c|c|}
\hline \multirow{2}{*}{$\begin{array}{c}\text { Pass } \\
\text { no. }\end{array}$} & \multirow{2}{*}{$\begin{array}{l}\text { Thickness } \\
\text { before rolling } \\
(\mathrm{mm})\end{array}$} & \multirow{2}{*}{$\begin{array}{l}\text { Thickness } \\
\text { after rolling } \\
\text { (mm) }\end{array}$} & \multicolumn{2}{|c|}{ Reduction } \\
\hline & & & $\begin{array}{l}\text { Unidirectional hot rolling } \\
\text { (UHR) }\end{array}$ & $\begin{array}{l}\text { Cross hot rolling } \\
\text { (CHR) }\end{array}$ \\
\hline 1 & 13.2 & 10.56 & $20 \%$ & $\begin{array}{c}20 \% \\
\text { (The pass interval rotates } 90^{\circ} \\
\text { along the vertical rolling plane) }\end{array}$ \\
\hline 2 & 10.56 & 7.88 & $25.38 \%$ & $25.38 \%$ \\
\hline
\end{tabular}

\section{Finite element model}

A 3D model for hot rolling was developed by the commercial finite element software MSC.

Marc (as shown in Fig. 2), mainly simulating the processes of UHR and CHR. The work roll was regarded as a rigid body with heat transfer, and the plate was an elastic-plastic body. The 8-noded hexahedral elements with good calculation accuracy and deformation performance were used for meshing in roll and plate. Considering the symmetry of the rolling process, only a half of the plate was modeled. To simplify complexity of it, the roll in contact with plate was meshed with biased density. In addition, the ideal boundary conditions that can be considered are portrayed in Fig. 3. As known, temperature and strain rate are very sensitive to rheological behavior, and hence the 
constitutive equation [25] established previously was taken into account to describe the formation of pure molybdenum in this paper. Updated Lagrangian method was employed to address the process of large plastic deformation. Mises yield criterion was given to the yield of material, and the interface contact behavior was complied with shear friction model. The relevant parameters considered are shown in Table 2.

Table 2. Input parameters used for simulation.

\begin{tabular}{ll}
\hline Material & Pure molybdenum \\
\hline Size $(\mathrm{mm})$ & $13.2 \times 50 \times 100$ \\
Number of elements & 19200 \\
Rolling speed $(\mathrm{rad} / \mathrm{s})$ & 2.6 \\
Initial temperature $\left({ }^{\circ} \mathrm{C}\right)$ & 1320 \\
Coefficient of friction & 0.3 \\
Contact heat transfer coefficient between plate and roll $\left(\mathrm{kW} \mathrm{m}^{-2} \mathrm{~K}^{-1}\right)$ & 10.5 \\
Integrated heat transfer coefficient to environment $\left(\mathrm{kWm}^{-2} \mathrm{~s}^{-1} \mathrm{~K}^{-1}\right)$ & 0.025 \\
The coefficient of plastic work dissipated into heat & 0.9 \\
The coefficient of friction work dissipated into heat & 0.95 \\
Air cooling time from heating furnace to rolling mill $(\mathrm{s})$ & 5.0 \\
The interval time between passes (s) & $2.5-3.0$ \\
\hline
\end{tabular}

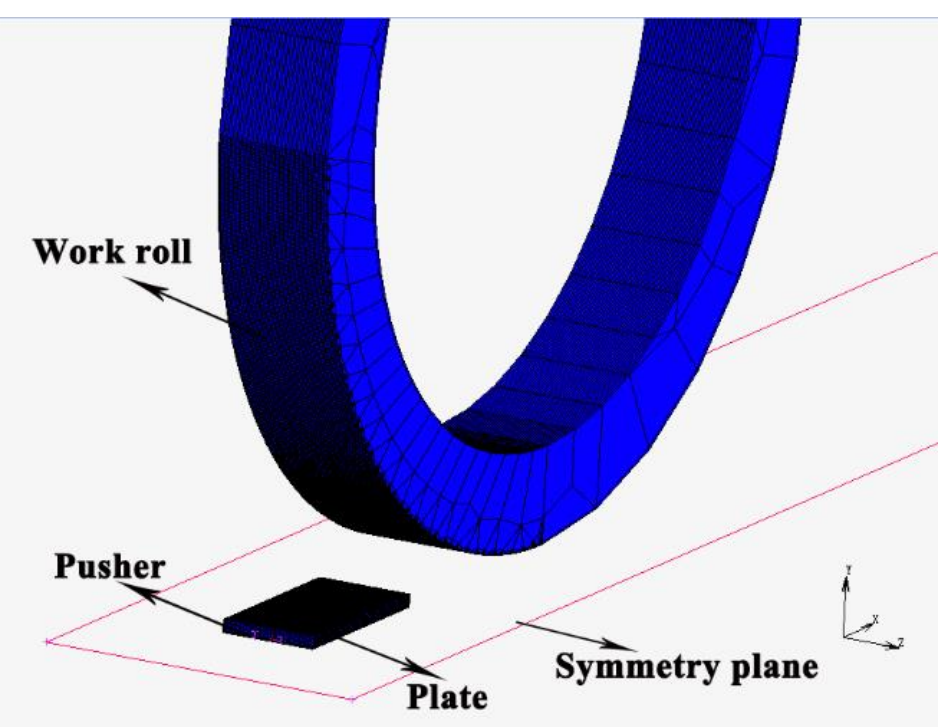

Fig. 2. Finite element model. 


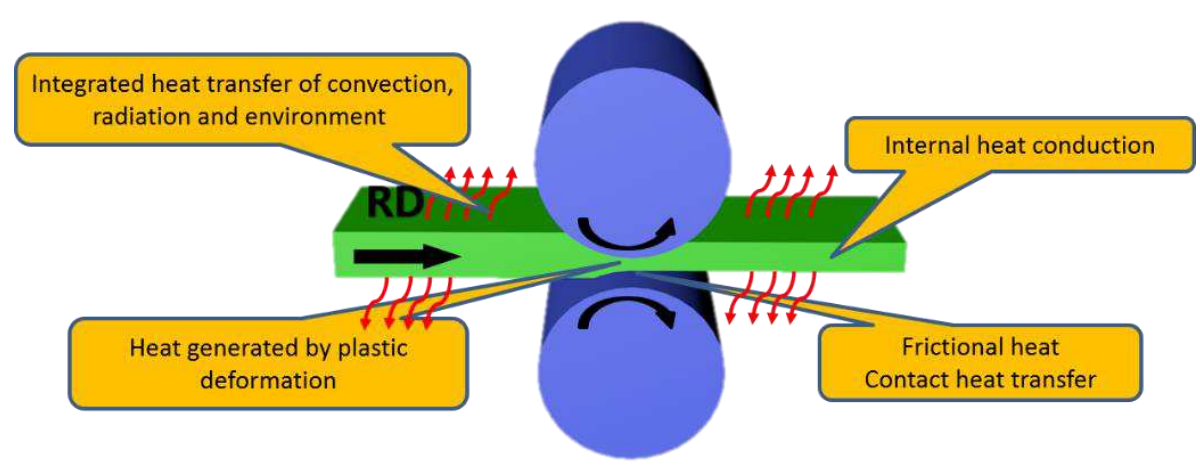

Fig. 3. Schematic diagram of boundary conditions during rolling process.

\section{Results and discussion}

\subsection{Analysis of deformation zone}

As displayed in Fig. 4, the typical historical characteristics of temperature field, stress and strain field before and after transition are discussed by taking the deformation zone and outer region (as marked by light cyan) as an example in the first pass of UHR. Note that AB is the center line of length, and DC is the symmetry line in width. The deformation zones of UHR and CHR are discussed and analyzed by using lines of $\mathrm{DC}$ and $\mathrm{AB}$ crossing their neutral planes respectively.

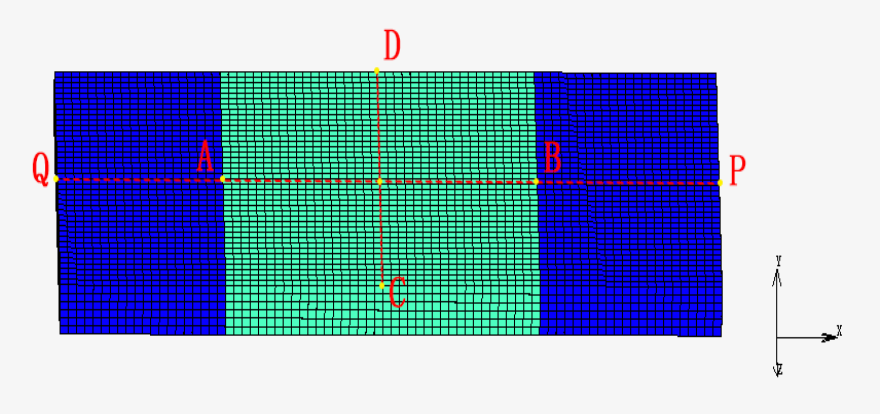

Fig. 4. Display of the selected deformation area.

\subsubsection{Temperature field}

The state of temperature field and temperature increment contour $(\mathrm{dT} / \mathrm{dt})$ of the first pass in deformation zone are shown in Fig. 5a and b respectively. It is obvious that the temperature distribution of the plate is inhomogeneous. There are three typical thermal phenomena in the plate 
of formation: a surface chilling, a surface reheating and an internal plastic heat generation. Concretely speaking, a severe chilling layer is generated on the surface of plate that is in contact with the roll, and internal distortion caused by plastic deformation occurs in the interior of the sheet, and then the conduction from the inside to the surface appears at the exit. In contrast with Fig. 5c and $\mathrm{d}$, it can be found that the temperature gradient in the longitudinal and transverse directions $(\mathrm{AB}, \mathrm{DC})$ before and after revolved is more competitive, and there is alternating floating. This is a result of the combined effects of heat inside the strip, thermal transfer on the interface of the sheet and rollers, as well as the convection and radiation between the plate surface and the surrounding environment. In other words, the evolution histories of these phenomena are attributed to dynamic thermal equilibrium of the plate in the energy transfer and heat loss.
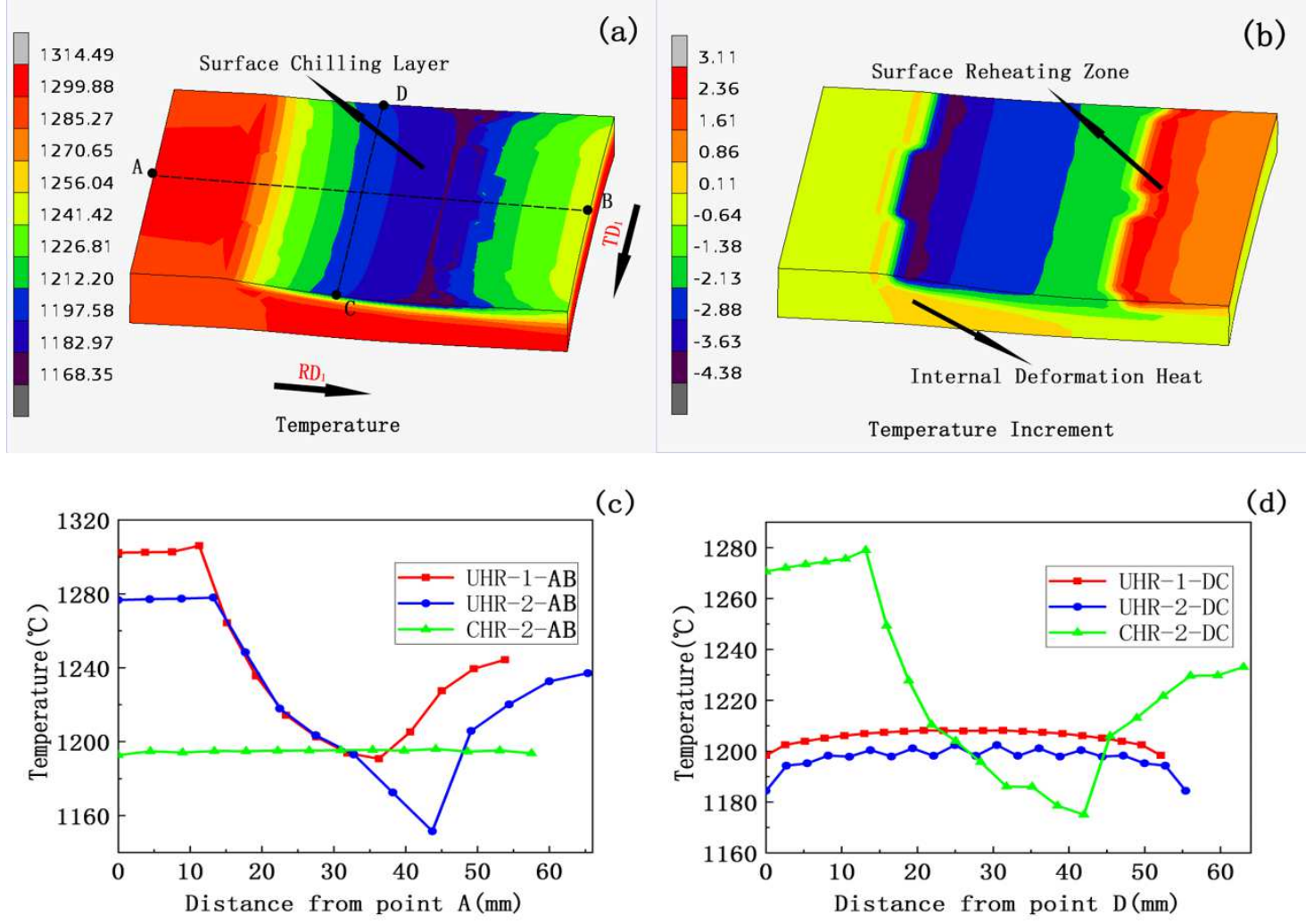

(c)

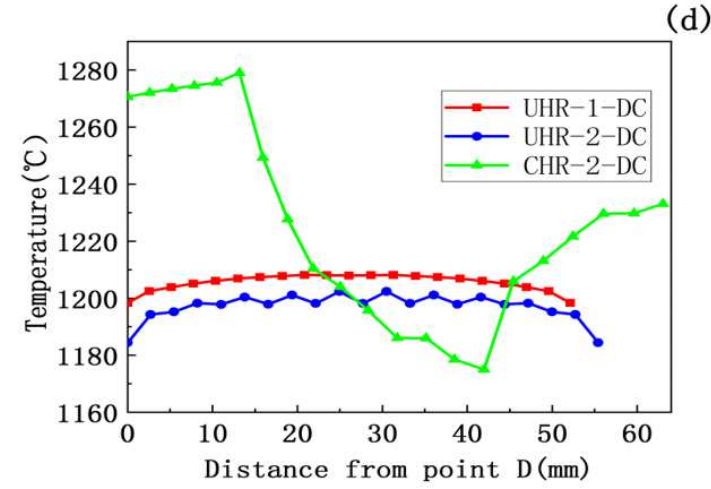

Fig. 5. The first pass in the deformation zone: a temperature field, $\mathbf{b}$ temperature increment contour (dT/dt); the temperature distributions of $\mathbf{c}$ and $\mathbf{d}$ are the lines of $\mathrm{AB}$ and DC under the two rolling conditions, respectively. 


\subsubsection{Stress field}

Stress, as the strength of internal force, reflects the equilibrium behavior of particles inside the body under external loads. Fig. 7a, $\mathrm{c}$ and e represent the distribution of equivalent stress in the longitudinal and transverse sections of the deformation zone in the first pass of UHR, the second pass of UHR and CHR, respectively. In general, no matter which rolling method is applied, the distribution of equivalent stress in the deformation zone is not homogeneous. The longitudinal section of Fig. 7a is clearly divided into: an inflexible domain (I), an easy deformation area (II) and two free deformation zones (III, IV). Among them, the inflexible domain is located on the surface, which bears severe friction stress in connection with roller, so the equivalent stress is the largest (208.74 MPa). With the deepening of deformation, the stress in the easy deformation area gradually decreases from the surface to the center. Since the free deformation zone is close to the outer region, its static obstruction is difficult to resist the compression behavior of the roller in the thickness of plate, so metal flow along the direction of $\mathrm{RD}_{1}$ is accelerating, resulting in the lowest equivalent stress in this area. Similar profiles are also observed in the longitudinal sections of c and e. In addition, there is a certain amount of prestress near the entrance and exit of the outer region, and the farther its distribution is from the deformation zone, the weaker intensity of the stress is.

In order to further explore the nature of the large metal flow gradient in the zones of III and IV, the internal force evolution of the entrance and exit at the junction of the free deformation zone and the outer zone is focus on analysis (as revealed in Fig. 6a, b, c and d). Furthermore, the state of additional stress in different orientations of rolling direction (RD), thickness direction (ND) and width direction (TD) is described in detail by means of microelements parallel to the coordinate plane. It is clearly seen that the surface at the entrance and exit, in two processes, has a tensile stress 
in directions of $\mathrm{RD}_{1}$ and $\mathrm{RD}_{2}$, while there is an additional compressive stress in the center, surprisingly. Specifically, in the first pass, the tensile stress on the surface is greater than that of compressive stress in the center, resulting in a larger force field gradient at the entrance and exit, while the compressive force in the core is dominant in the second pass of UHR, which makes the plate exhibit compressibility along the thickness. Similarly, the difference competition in tension/compression stress between the surface and center appears to be smaller in CHR. That is to say, the coexistence of tension and compression between the surface and center can significantly diminish the stress difference and substantially drop the ununiformity along the thickness direction, i.e., " synchronization effect." With the increase of rolling passes, the plate becomes thinner, which also shows that the equivalent stress along the thickness direction has basically penetrated into the center, which is of great significance for the micro-porosity welding, the atoms reach the gravitational range of metal bond, and completing the microstructure transformation from the sintering state to rolling. Moreover, the $\sigma_{y}$-effect along the thickness direction is negative under these rolling modes, compared with $\mathrm{CHR}$, the integral compression effect of UHR seems to be more acute. And along the direction of $\sigma_{z}$, the compressibility under the two processes is quite weakened, which indicates that there may be a certain pre-tension stress trend from the central section to edge in each direction of width $\left(\mathrm{TD}_{1} / \mathrm{TD}_{2}\right)$ before and after rotation, promoting the formation of spreading. 

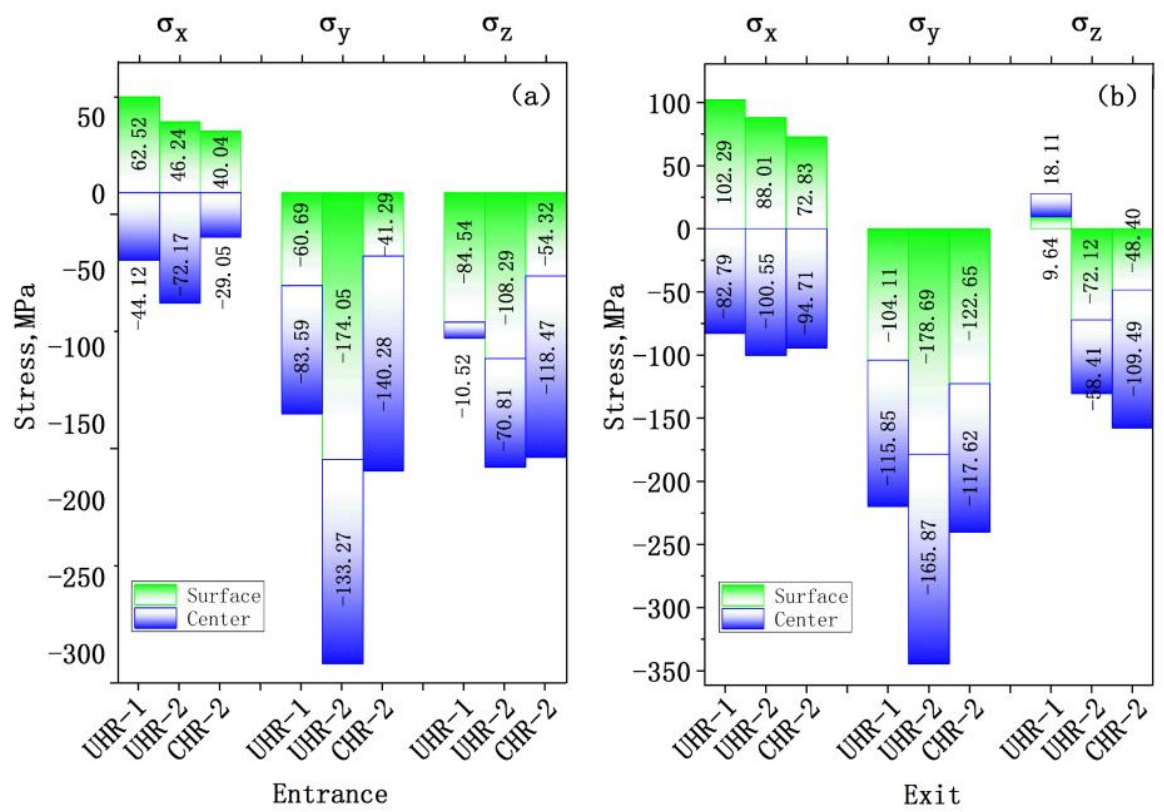

Fig. 6. The distribution of additional stress at the entrance and exit of different passes under the conditions of UHR and CHR.

It can indicate from Fig. 7a and $\mathrm{h}$ that the equivalent stress of the first pass of UHR is under the range of 195.6-199.2 MPa, and its fluctuation is very small. The distribution increases slightly from the center to the edge of the plate and then decreases gradually on the transverse surface, which can be explained in more detail by Fig. 7b. Although the elements in central region are forced to flow along $\mathrm{RD}_{1}$ and $\mathrm{TD}_{1}$ by the pressure of the rolls, the severe interfacial friction behavior of the plate-roll is reproduced, so that the directions of $\mathrm{RD}_{1}$ and $\mathrm{TD}_{1}$ are subject to the constraint of compressive stress, that is, the middle is in a state of three-dimensional compressive stress. Quite evidently, the effect of three-dimensional compressive stress is weakening from the middle of the sheet to the edge area. Especially the interface friction resistance decreases significantly along the $\mathrm{TD}_{1}$ direction at the edge of the plate, which enhances the width spread gradually, and $\sigma_{z}$ drops to zero. According to the law of volume invariance, the elongation in the rolling direction decreases with the increase of spreading in width, so the tensile stress is produced 
in the direction of $\mathrm{RD}_{1}$. Thus, a compression-tension stress state is on the edge of the plate. Additionally, the rapid temperature loss caused by convection and radiation between the edge of plate and environment is also an objective factor that causes the larger stress on the edge. Comparing Fig. 7c and h, the equivalent stress of the second pass of UHR is in the range of 231.0-234.6 MPa. However, the differentiation of stress from the middle to the edge seems to be even worse, which is closely related to the stronger genetic characteristics of passes of the molybdenum slab, explaining in the fig. $7 \mathrm{~d}$. As the reduction is stepped on, the friction resistance along the direction of $\mathrm{TD}_{1}$ is strikingly enhanced, and the compressibility of the $\sigma_{z}$ permeates to the edge profile of the sheet (points C and D), the width spread is further limited. simultaneously conclusion is on the law of volume invariance that the decrease of width spread leads to the increasing of ductility along $\mathrm{RD}_{1}$ direction, and the tensile stress of $\sigma_{x}$ decreases sharply. It is remarkable that the peak value of the second pass of $\sigma_{x}$ is apparently larger than that of the first, which is also closely related to the existence of temperature dropping at the edge.

The distribution of equivalent stress in the second pass of CHR is shown in Fig. 7e. the exchange of the rolling direction makes the stress along $\mathrm{AB}$ and $\mathrm{CD}$ changes alternately because the plate is rotated $90^{\circ}$ perpendicular to the rolling plane, and the uniformity of equivalent stress is significantly better than that of UHR. From Fig. $7 \mathrm{~g}$ and $\mathrm{h}$, it can be seen that equivalent stress of the line $\mathrm{AB}$ is distributed in the range of 44.9-207.9 MPa during the first pass of UHR, but it increases to 251.6-253.7 MPa after CHR. Similarly, the equivalent stress at the exit of deformation zone on line DC after CHR basically maintains at $134.9 \mathrm{MPa}$, reflecting that $\mathrm{CHR}$ has a great contribution to the improvement of excessive residual stress at the edge of UHR. Combined with the analysis in Fig. 
$7 \mathrm{~b}$ and $\mathrm{f}$, it is found that the additional stress originally in $\mathrm{RD}_{1}$ is all converted into compressibility on line $\mathrm{AB}$, while the compressive stress of $\sigma_{z}$ in $\mathrm{TD}_{1}$ is replaced by the tensile stress $\sigma_{x}$ in $\mathrm{RD}_{2}$ on line $\mathrm{DC}$, which is conducive to the ductility of the plate along the direction of $\mathrm{RD}_{2}$. The tensile stress of $\sigma_{x}$ in $\mathrm{RD}_{1}$ is transformed into the compressive stress of $\sigma_{z}$ in $\mathrm{TD}_{2}$, and $\sigma_{z}>\sigma_{x}$. this can not only limit the width spread along $\mathrm{TD}_{2}$ in $\mathrm{CHR}$, but also greatly repair the tensile stress band at the edge of UHR, especially in the bite phase and tail stage. the residual tensile stress along lines of $\mathrm{AB}$ and $\mathrm{DC}$ has taken place after the completion of rolling action on the surface of the outer zone.

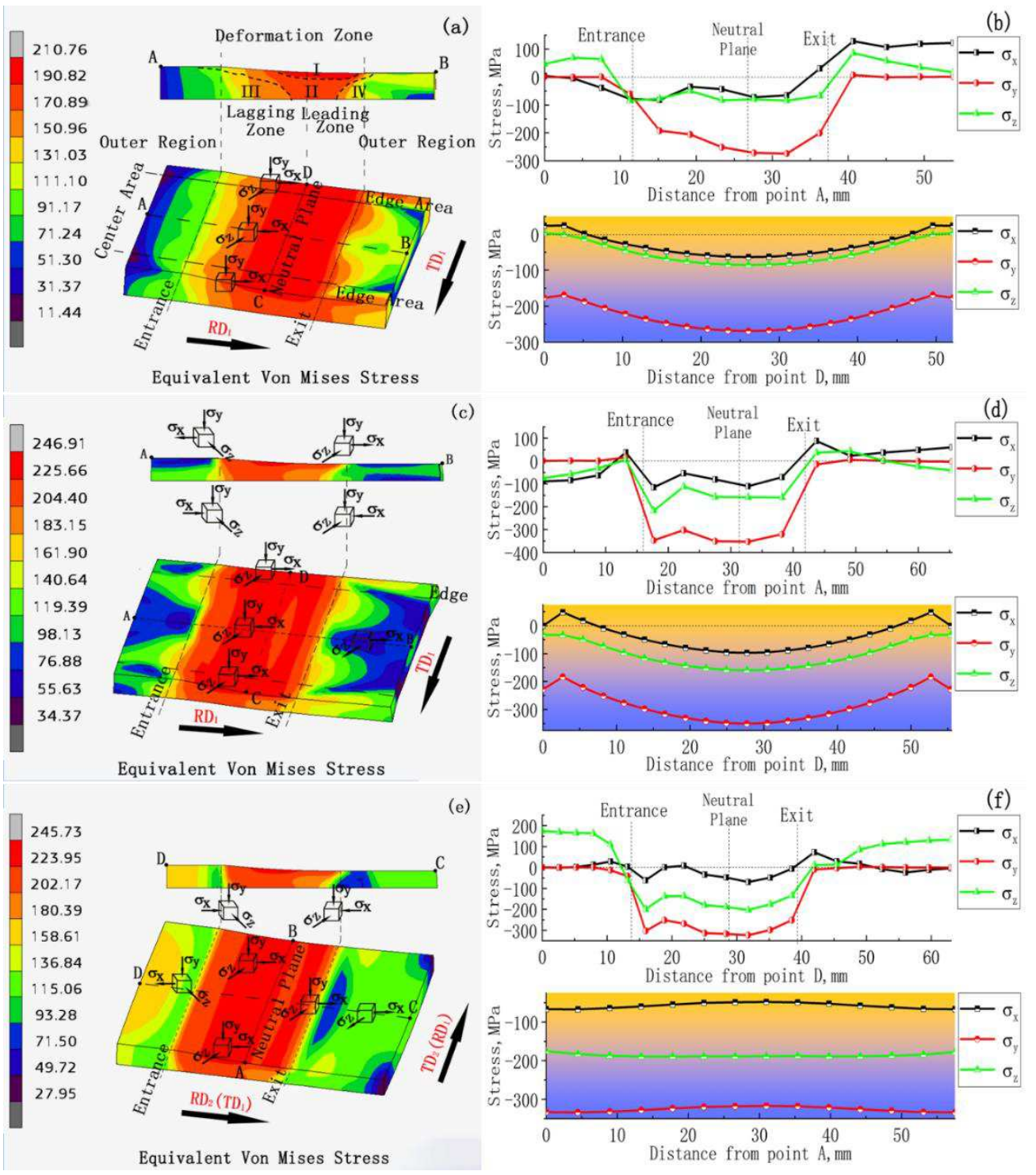



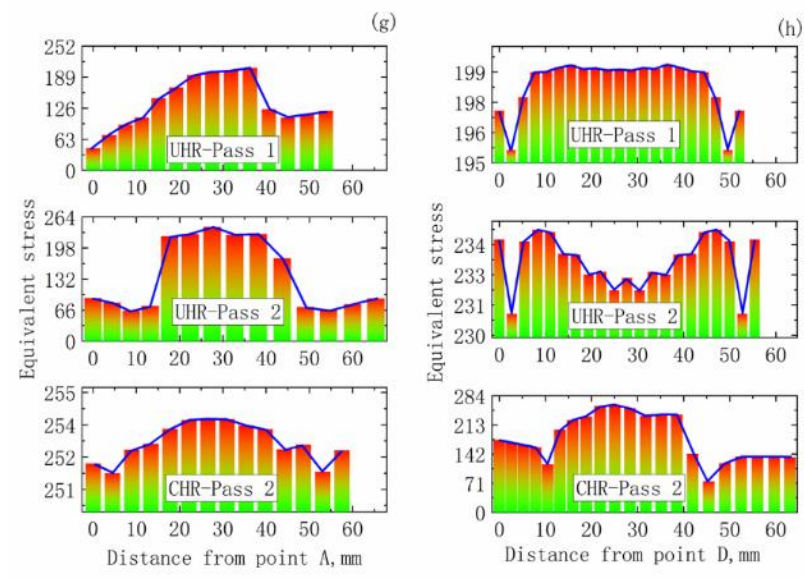

Fig. 7. Equivalent stress distribution in rolling deformation zone a the first pass of UHR; $\mathbf{c}$ the second pass of UHR; $\mathbf{e}$ the second pass of CHR; $\mathbf{b}, \mathbf{d}$, and $\mathbf{f}$ are the additional stress distributions along $\mathrm{AB}$ and $\mathrm{DC}$ for each of the above passes; $\mathbf{g}$ and $\mathbf{h}$ are the equivalent stress curves of different passes along $\mathrm{AB}$ and $\mathrm{DC}$.

Based on the above discussion, the fundamental reason for the formation of the stress field in the deformation zone under the two rolling methods is the combination action of the rolling stress, the contact friction and the resistance in outer zone [19]. The tensile stress in direction of RD is beneficial to the longitudinal elongation, and the compressive stress in ND can markedly heighten the shaping along the thickness direction, improving the hydrostatic pressure [26], the aggravation of width spread is limited by the existence of compressive stress in TD of the sheet. What is interesting is that there are three-dimensional compressive stresses in both longitudinal and transverse directions in the deformation zone and $\sigma_{y}>\sigma_{z}>\sigma_{x}$. It is known to us all that, based on the plastic mechanics theory, the existence of three-dimensional compressive stress is of great importance for perfecting the microstructure, improving the plasticity of materials and decreasing the possibility of crack source formation.

\subsubsection{Strain field}


The permanent deformation caused by continuous particle migration to the original position under the applied stress state is a key index to measure the plastic capacity, which directly determines the displacement directions of the mass points and then produces plastic strain. The distribution of equivalent plastic strain in UHR is shown in Fig. 8a and c. An ununiform strain of pure molybdenum in directions of thickness and transverse is resulted from the discrepancy of stress field. The strain history curve of line $A B$ in the deformation zone under the two processes is clarified in Fig. 8g. Under the pressure penetration of the roll along the thickness direction of the plate, the surface bears a larger plastic strain, while the center produces a smaller plastic strain. From the analysis of the stress field in section 4.1 .2 , it is the fact that the middle of the plate surface suffers the three-dimensional compressive stress and the action of interface shear causes a significant surge in $\mathrm{RD}_{1}$ to $\varepsilon_{\times}$. From the entrance to exit of the deformation zone, the equivalent strain accumulates continuously along the rolling direction, and the difference of the equivalent plastic strain between the surface and the center is narrowing, indicating that the thinning of the thickness makes the stress tend to be consistent along the thickness direction, so that the strain is relatively uniform, especially the metal grains are forced to cross the neutral plane to leading zone. Compared with a, $\mathrm{c}$ and $\mathrm{h}$ in Fig. 8, the equivalent plastic strain in the first pass on the wide-directional DC is about 0.2 , while that in the second pass is maintained at about 0.54 . Even the difference is very small, there is still a slight increase from the center to the edge, especially the large peaks near the edge. It can be explained, combined with Fig. $8 \mathrm{~b}$ and d, that the boundary friction constraint is less than that of the middle, so that the compressive stress $\sigma_{z}$ in $\operatorname{TD}_{1}$ is 
weakened, and $\varepsilon_{z}$ presents a tensile strain distribution. It should be noted that $\varepsilon_{z}$ in the middle of the sheet is larger than that on edges, while $\varepsilon_{x}$ and $\varepsilon_{y}$ are on the contrary.

The equivalent strain in Fig. 8e under CHR is obviously better than that of UHR when the plate is rotated $90^{\circ}$ perpendicular to the rolling plane. Fig. $8 \mathrm{~h}$ shows that the equivalent strain trend of longitudinal line $\mathrm{DC}$ is basically the same as the longitudinal line $\mathrm{AB}$, but it is the change of the strain path that makes the edges in $\mathrm{TD}_{1}$ of strain state significant improvement in UHR, while the equivalent strain of $\mathrm{TD}_{2}$ on line $\mathrm{AB}$ is about 0.56 . In the light of deduction in Fig. $8 \mathrm{~d}$ and $\mathrm{f}$ as follows: the additional tensile strain $\varepsilon_{x}$ and $\varepsilon_{z}$ along lines of $\mathrm{AB}$ and $\mathrm{DC}$ are alternately compensated after the vertical and horizontal cross-exchange of the plate surface, which greatly enhances the extension of the plate along $\mathrm{TD}_{2}$. It is not similar to the stress field, there are two-dimensional tensile strains $\left(\varepsilon_{x}\right.$ and $\left.\varepsilon_{z}\right)$ and uniaxial compressive $\operatorname{strain}\left(\varepsilon_{y}\right)$ in the deformation zone, and $\varepsilon_{y}>\varepsilon_{\times}>\varepsilon_{z} . \varepsilon_{\times}$is helpful to the extension of plate along $\mathrm{RD}_{1}$ and $\mathrm{RD}_{2}$, $\varepsilon y$ mainly contributes to the compression deformation along the thickness direction, while the transverse tensile strain $\varepsilon_{z}$ gradually decreases from the center to the edge, and the resulting spread is negligible. That is to say, the change of the strain path causes the length and width of the plate to be interchanged, which significantly compensates for the ductility in the $\mathrm{TD}_{1}$ direction, improving the anisotropy of the plate and the potential performance along the width direction in UHR. 
(a)

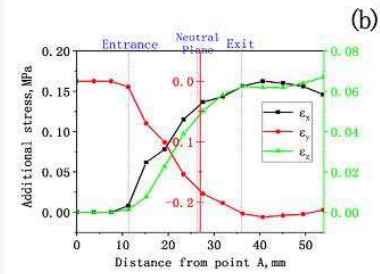

Outer Region Lagging'Leading Outer Region

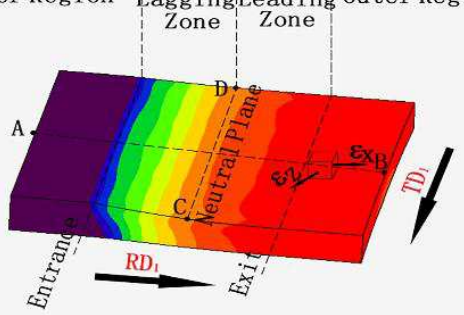

Total Equivalent Plastic Strain

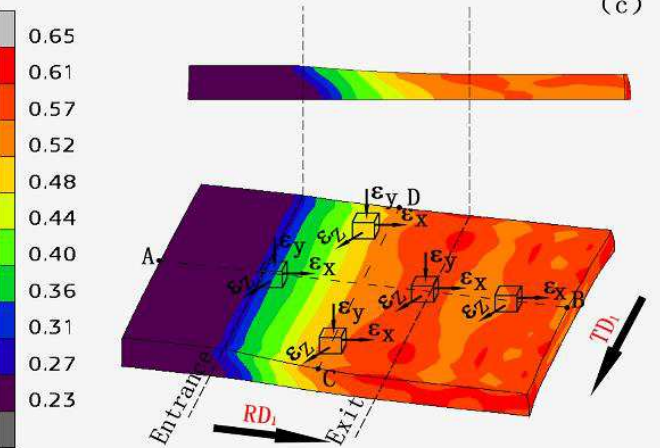

Total Equivalent Plastic Strain

(e)
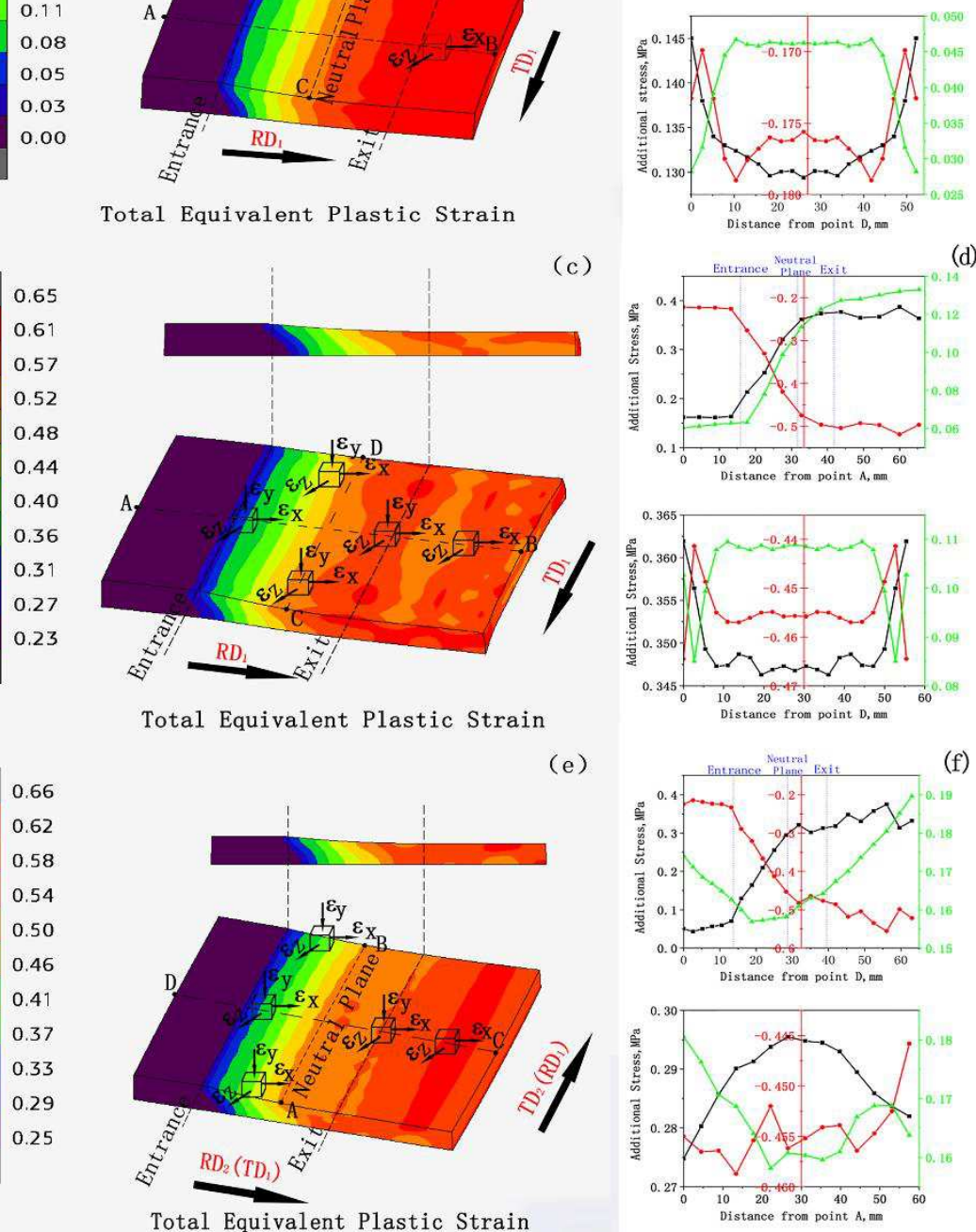
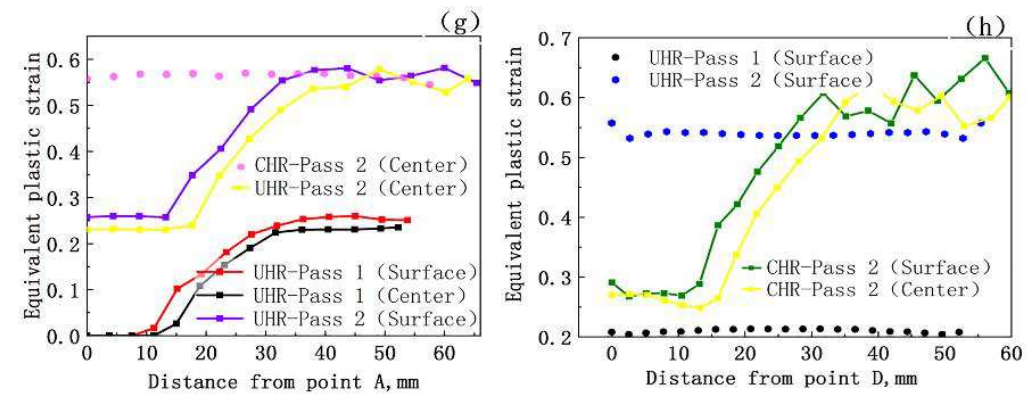

Fig. 8. The contour maps of equivalent plastic strain in the rolling deformation zone: a the first pass; $\mathbf{c}$ the second pass in UHR; $\mathbf{e}$ the second pass in CHR; $\mathbf{b}, \mathbf{d}$ and $\mathbf{f}$ are the distributions of additional strain along lines of $\mathrm{AB}$ and $\mathrm{DC}$ in each pass respectively; $\mathbf{g}$ and $\mathbf{h}$ are the evolution of equivalent strain along lines of $\mathrm{AB}$ and $\mathrm{DC}$, respectively. 


\subsection{Optimization of process parameters}

In summary, the evolution of fields in the rolling deformation zone is peculiarly prone to temperature, stress, and strain, and they jointly contribute to the thermal rheological behavior of pure molybdenum. To further determine the reasonable range of processing parameters, the effects of processing parameters on the depth of surface chilling layer, additional tensile stress in wide direction and additional strain in rolling direction are studied.

\subsubsection{Effect of machining parameters on surface chilling layer}

The intense contact between high-temperature molybdenum and cold roll will badly affect the temperature gradient of the sheet on surface. As depicted in Fig. 9a and b, taking a single pass as an example, the effects of different initial rolling temperatures and reductions on the surface chilling layer are studied under specific conditions. For molybdenum, it is obvious that the depth of the surface chilling remains basically the same under different situations (approximately 1/6 $\mathrm{H},<2.2$ $\mathrm{mm}$ ), which is equivalent to the Mg alloy plate [14]. But the chilling effect is only about $1 / 40 \mathrm{H}$ during rough rolling [27]. That means that the low-temperature surface of molybdenum is much thicker than that of steel, and the plate temperature is extremely sensitive to the action of cold roll. Thus, molybdenum is not convenient to address than other metals.
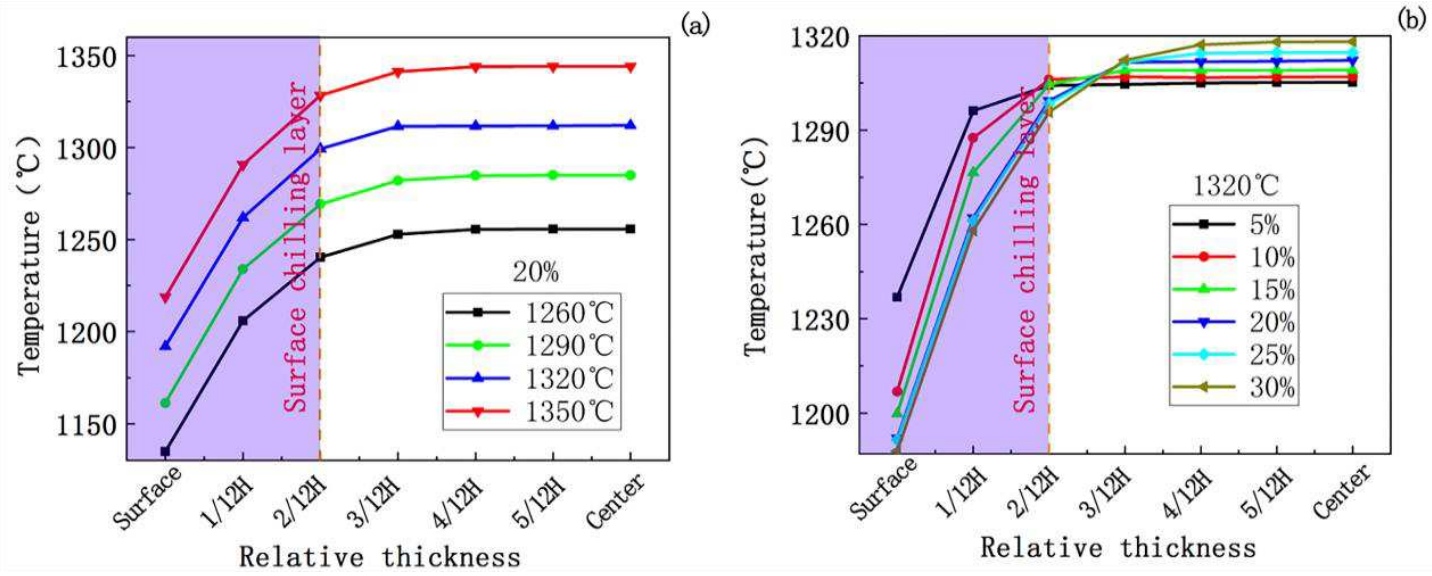
Fig. 9. Effects of $\mathbf{a}$ initial rolling temperature and $\mathbf{b}$ reduction on temperature distribution along thickness direction at the exit.

\subsubsection{Effect of processing parameters on the additional stress along the width of plate}

In the case of other conditions unchanged, the influence of different reduction and friction coefficient on the distribution of $\sigma_{x}$ along the width direction at the neutral surface in the second pass of the two rolling models was studied in Fig. 10a, b, c, and d. Obviously, both UHR and CHR have tensile/compressive stress distribution in their wide directions. As the amount of reduction increases, concretely speaking, the tensile stress in the edge region continues to worsen and has a tendency to extend to the middle, while it is just opposite with the increase of friction coefficient. It is worth noting that the maximum compressive stress in $\mathrm{CHR}$ is not in the core, but emerges in approximately $1 / 4$ of the length. Owing to the rotation of the plate along the rolling plane, the contact area raises sharply, resulting in a prominent difference of the aspect ratio of resistance under a larger width, which may cause a certain degree of convexity or distortion in the middle of the plate. 

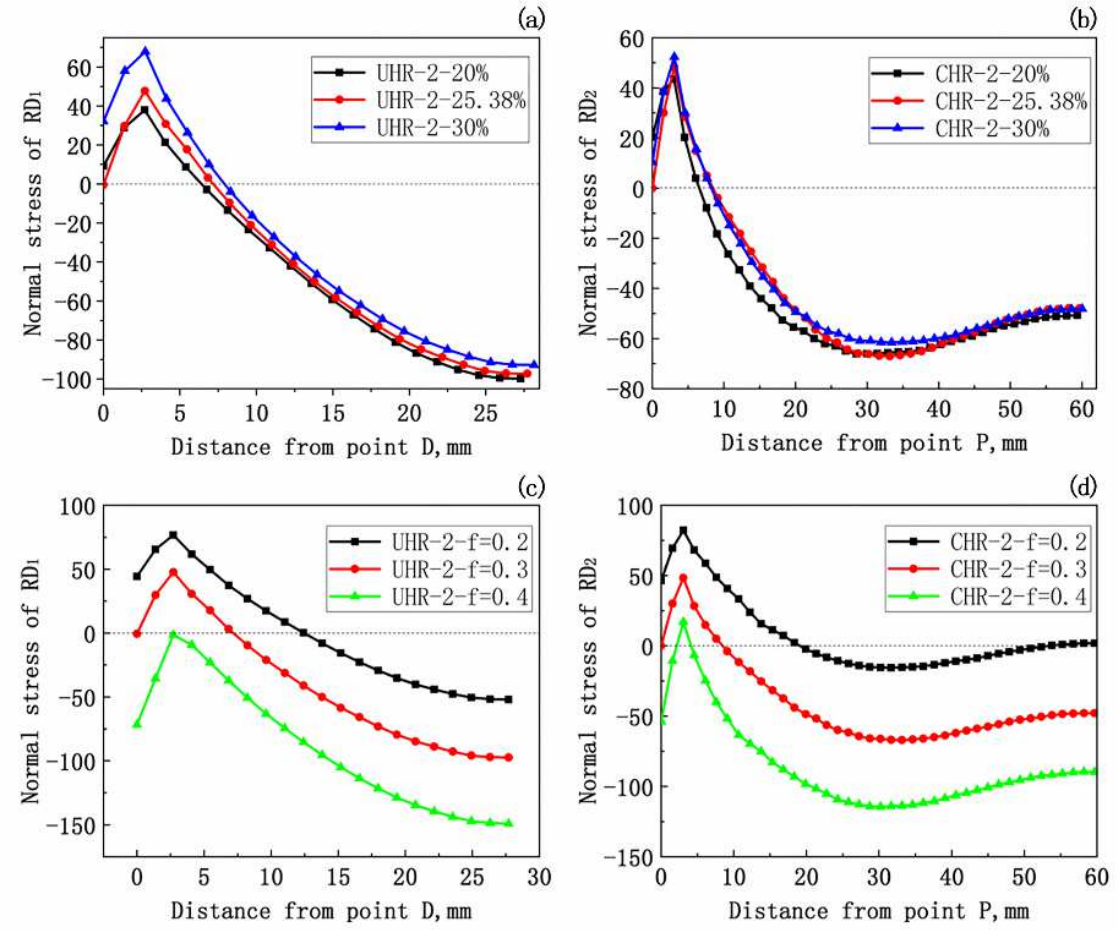

Fig. 10. The effect of different parameters on the distribution of $x$-direction tensile stress along the

width direction on the neutral surface under the two rolling modes: $\mathbf{a}$ and $\mathbf{b}$ reduction; $\mathbf{c}$ and $\mathbf{d}$

friction coefficient.

\subsubsection{Effect of reduction on additional strain in rolling direction}

With the accumulation of reduction, the strain change of nodes on the plate surface is different, but the regular pattern is basically the same. A certain point on the surface of the sheet is selected as the tracking object, and focused on the history of plastic strain along the $\mathrm{x}$-direction during the second passes of UHR and CHR, as described in Fig. 11a and b. The plastic strain along the $\mathrm{x}$-direction accumulates steadily in the longitudinal direction with the continuous reductions, resulting in serious anisotropy of the plate during UHR. Even if the reduction of the second pass is consistent with that of the first pass in CHR, the strains in directions of $\mathrm{RD}_{1}$ and $\mathrm{RD}_{2}$ cannot be balanced after the cross reversing of the plate. When the reduction is controlled at about $10 \%$, the difference of strain peaks between the longitudinal and transverse is the smallest. This is because 
the change of the rolling direction makes the sheet inherit the transverse strain in $\mathrm{TD}_{1}$ direction before the second pass, forming a wave trough, and then expanding along that position step by step, a secondary wave peak is taken place. This proves that under this condition, the cross-rolling is very advisable for cutting down the anisotropy of the plate.
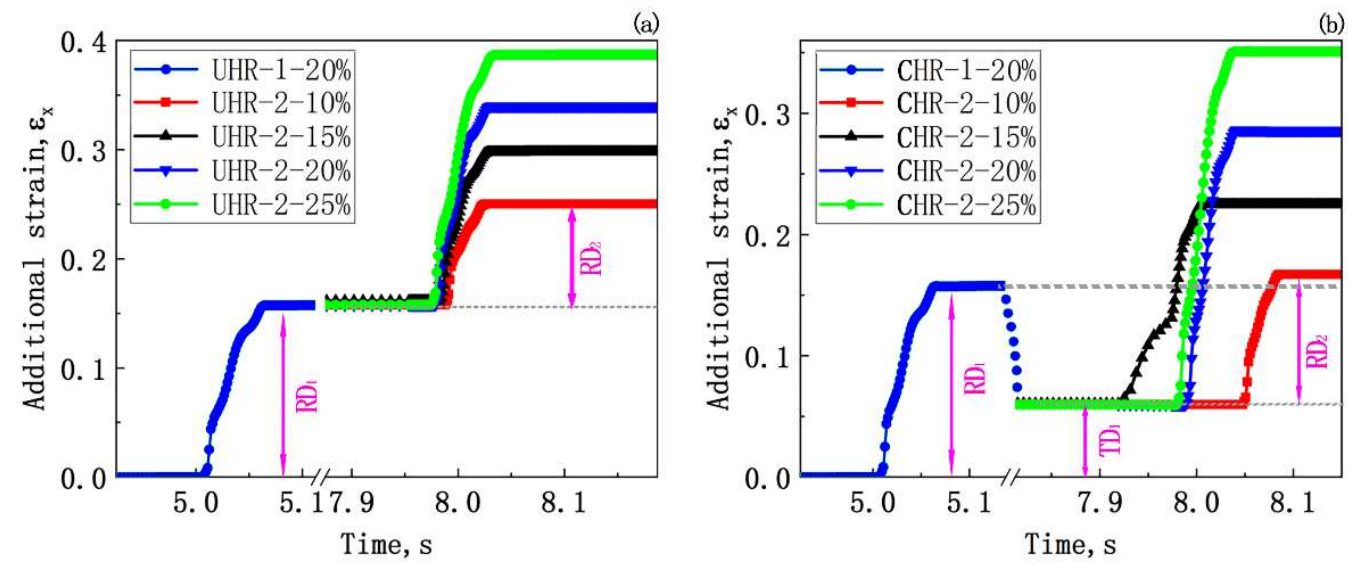

Fig. 11. Effect of different reductions on plastic strain at a point on the plate surface along x-direction: a UHR; b CHR

\subsection{Validation process}

In order to further verify the accuracy of the models, infrared pyrometer was used to measure the surface temperature of plates in each pass. For the determination of rolling force, considering the complexity of molybdenum billet rolling, the classical Sims equation [28] was employed for theoretical verification. The specific process is shown in Fig. 12 and Table 3. It can be seen that the prediction of rolling force is basically in line with the actual, but there is a certain error between the simulated surface temperatures and the measured values. The reason is that the $\mathrm{N}$ and $\mathrm{O}$ in the air will interact with molybdenum at high temperatures to produce oxidation suction phenomenon, and thus a smear layer $\left(\mathrm{MoN}, \mathrm{MoO}_{3}\right)$ is formed, resulting in errors in pyrometer readings. Even if there is a certain error in the models, the high-temperature rheological behavior of molybdenum plates 
can be preliminarily predicted, laying a certain foundation for the subsequent production of molybdenum sheets.

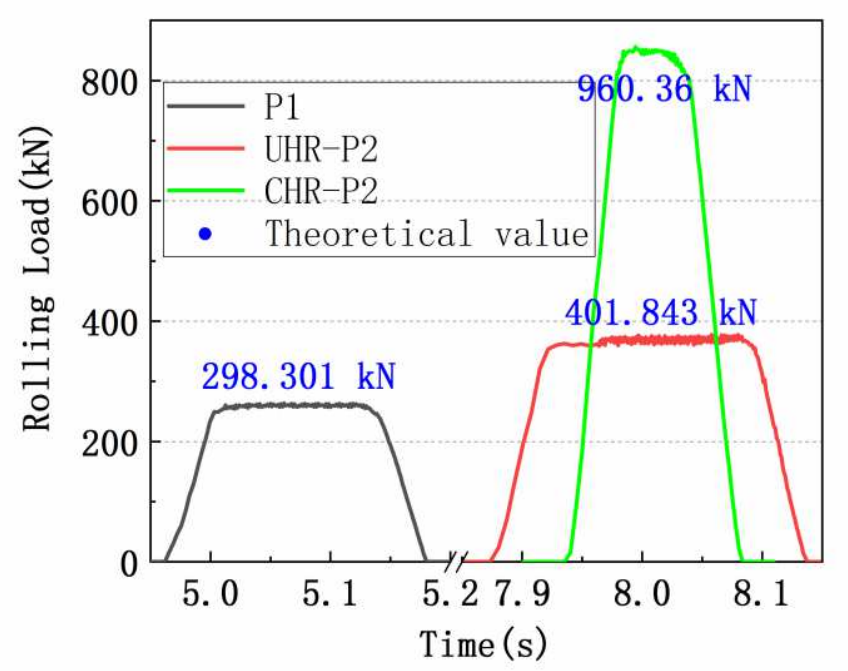

Fig. 12. Comparison of theoretical rolling force and simulated rolling force under UHR and CHR.

Table 3. Temperature comparison between the measured values and the simulated on the surface of the plates.

\begin{tabular}{ccc}
\hline & Simulation values & Experimental values \\
\hline Before the first pass & $1298.5^{\circ} \mathrm{C}$ & $1307.8^{\circ} \mathrm{C}$ \\
Before the second pass (UHR) & $1273.2^{\circ} \mathrm{C}$ & $1261.6^{\circ} \mathrm{C}$ \\
Before the second pass (CHR) & $1271.9^{\circ} \mathrm{C}$ & $1253.5^{\circ} \mathrm{C}$ \\
\hline
\end{tabular}

\section{Conclusions}

The following conclusions can be drawn by applying numerical simulation to UHR and CHR of pure molybdenum sheets:

(1) There are three typical thermal phenomena in the evolution of temperature field: surface chilling layer, internal plastic deformation heat generation and surface reheating zone after rolling. The reason why the distinction of temperature field in length and breadth is that the contact area of the plate and roller is different during the process of plate rolling in alternate direction. The surface quenching depth of pure molybdenum plate is about $1 / 6 \mathrm{H}$ under different initial temperatures and reductions. 
(2) The stress and strain field distributions of pure molybdenum sheets are all nonuniform, and the fundamental reason is that the rolling stress, contact friction and external resistance are jointly affected. The characteristic three-dimensional compressive stress exists in the rolling deformation zone, and $\sigma_{y}>\sigma_{z}>\sigma_{x}$, while the strains are uniaxial compressive stress and two-dimensional tensile stress, and $\varepsilon_{y}>\varepsilon_{x}>\varepsilon_{z}$.

(3) Under the two processes, the existence of edge tensile stress along the width direction increases with the aggravation of reduction and the decrease of friction coefficient. Compared with UHR, CHR is helpful to reduce the anisotropy of the plate.

Authors' contributions: Ping $\mathrm{Hu}$ and Quan Cheng proposed and carried out the analysis of simulation. Hairui Xing and Shilei Li assisted in the design and ideas of the verification experiment. Jiayu Han, Songwei Ge and Hua Xingjiang were responsible for the measurement and detection in experiment. Boliang Hu, Kuaishe Wang and WenZhang further evaluated the Process simulation.

Funding: This work was supported by the National Key R\&D Program of China (2017YFB0305600, 2017YFB0306000), the Fok Ying Tung Education Foundation (171101), the Youth Innovation Team of Shaanxi Universities (2019-2022), the Top young talents project of "special support program for high level talents" in Shaanxi Province (2018-2023) and the Major scientific and technological projects in Shaanxi Province of China (2020ZDZX04-02-01).

Data availability: Not applicable.

\section{Compliance with ethical standards}

Ethics approval: The research does not involve human participants or animals and the authors warrant that the paper fulfills the ethical standards of the journal. This manuscript has not been published or presented elsewhere in part or in entirety and is not under consideration by another journal.

Consent to participate: The research does not involve human participants or animals and the authors warrant that the paper fulfills the ethical standards of the journal. 
Consent to publish: All authors are consent to publish this manuscript in The International Journal of Advanced Manufacturing Technology.

Competing interests: The authors declare that they have no conflict of interest.

\section{References}

1. Liu G, Zhang GJ, Jiang F, Ding XD, Sun YJ, Sun J, Ma E (2013) Nanostructured highstrength molybdenum alloys with unprecedented tensile ductility. Nat Mater 3544:344-350

2. Wang X, Li P, Xue KM (2015) An analysis on microstructure and grain size of molybdenum powder material processed by equal channel angular pressing. J Mater Eng Perform 24: $4510-4517$

3. Chakraborty SP, Banerjee S, Sharma IG, Suri AK (2010) Development of silicide coating over molybdenum based refractory alloy and its characterization. J Nucl Mater 403:152-159

4. Kobayashi S, Tsurekawa S, Watanabe T (2005) Grain boundary hardening and triple junction hardening in polycrystalline molybdenum. Acta Mater 53:1051-1057

5. Ahmadi E, Malekzadeh M, Sadrnezhaad SK (2011) Preparation of nanostructured high temperature TZM alloy by mechanical alloying and sintering. Int J Refract Met Hard Mater 29:141-145

6. Primig S, Clemens H, Knabl W, Lorich A, Stickler R (2015) Orientation dependent recovery and recrystallization behavior of hot-rolled molybdenum. Int J Refract Met Hard Mater 48: $179-186$

7. Hu P, Zhou YH, Deng J, Li SL, Chen WJ, Chang T, Hu BL, Wang KS, Feng PF, Volinsky AA (2018) Crack initiation mechanism in lanthanum-doped titanium-zirconium-molybdenum alloy during sintering and rolling. J Alloys Compd 745:532-537 
8. Cockeram BV (2010) The role of stress state on the fracture toughness and toughening mechanisms of wrought molybdenum and molybdenum alloys. Mater Sci Eng A 528:288-308

9. Xing HR, Hu P, Zhou YH, Li SL, Zuo YG, Cheng Q, Wang KS, Yang F, Feng PF, Chang T (2020) The microstructure and texture evolution of pure molybdenum sheets under various rolling reductions. Mater Charact 165:110357

10. Galantuccia LM, Tricarico L (1999) Thermo-mechanical simulation of a rolling process with an FEM approach. J Mater Process Tech 92-93:494-501

11. Zhang SH, Zhang GL, Liu JS, Li CS, Mei RB (2010) A fast rigid-plastic finite element method for online application in strip rolling. Finite Elem Anal Des 46:1146-1154

12. Mohebbi MS, Akbarzadeh A (2018) Constitutive equation and FEM analysis of incremental cryo-rolling of UFG AA 1050 and AA 5052. J Mater Process Tech 255:35-46

13. Dixit US, Dixit PM (1997) Finite-element analysis of flat rolling with inclusion of anisotropy, Int J Mech Sci 39:1237-1255

14. Fiorentino A, Ceretti E, Giardini C (2013) Tube hydroforming compression test for friction estimation-numerical inverse method, application, and analysis. Int J Adv Manuf Technol 64:695-705

15. Bagheripoor M, Bisadi H (2011) Effects of rolling parameters on temperature distribution in the hot rolling of aluminum strips. Appl Therm Eng 31:1556-1565

16. Rout M, Pal SK, Singh SB (2016) Finite element simulation of a cross rolling process. J Manuf Process 24:283-292

17. Rout M, Pal SK, Singh SB (2018) Prediction of edge profile of plate during hot cross rolling. J 
Manuf Process 31:301-309

18. Wang F (2017) Deposition characteristic of Al particles on Mg alloy micro-channel substrate by cold spray. Int J Adv Manuf Technol 91:791-802

19. Hao PJ, He AR, Sun WQ (2018) Formation mechanism and control methods of inhomogeneous deformation during hot rough rolling of aluminum alloy plate. Arch Civ Mech Eng 18:245-255

20. Lu YH, Zhu SC, Zhao ZT, Chen TL, Zeng J (2020) Numerical simulation of residual stresses in aluminum alloy welded joints. J Manuf Process 50:380-393

21. Kleiser G, Revil-Baudard B, Pasiliao CL (2016) High strain-rate plastic deformation of molybdenum: Experimental investigation, constitutive modeling and validation using impact tests. Int J Impact Eng 96:116-128

22. Priel E, Mittelman B, Trabelsi N, Cohen Y, Koptiar Y, Padan R (2019) A computational investigation of Equal Channel Angular Pressing of molybdenum validated by experiments. J Mater Process Tech 264:469-485

23. Zhang XX, Yan QZ, Lang ST, Wang YJ, Ge CC (2017) Preparation of pure tungsten via various rolling methods and their influence on macro-texture and mechanical properties. Mater Des 126:1-11

24. Fan HY, Liu SF, Li LJ, Deng C, Liu Q (2016) Largely alleviating the orientation dependence by sequentially changing strain paths. Mater Des 97:464-472

25. Hu P, Cheng Q, Li SL, Xing HR, Han JY, Ge SW, Hua XJ, Hu BL, Wang KS, Li LP (2020) Rheological behavior of pure molybdenum at high temperature considering strain compensation. Adv Eng Mater 2000661 
26. Nalawade RS, Puranik AJ, Balachandran G, Mahadik KN, Balasubramanian V (2013) Simulation of hot rolling deformation at intermediate passes and its industrial validity. Int $\mathbf{J}$ Mech Sci 77:8-16

27. Chen WC, Samarasekera IV, Hawbolt EB (1993) Fundamental phenomena governing heat transfer during rolling. Metall Trans A 24:1307-1320

28. Parteder E, Zeman K, Du HY, Grill R (2012) Recalculation of flow stresses from industrial process data for heavy plate rolling using a 2D finite element model. steel res Int 83:124-130 


\section{Figures}

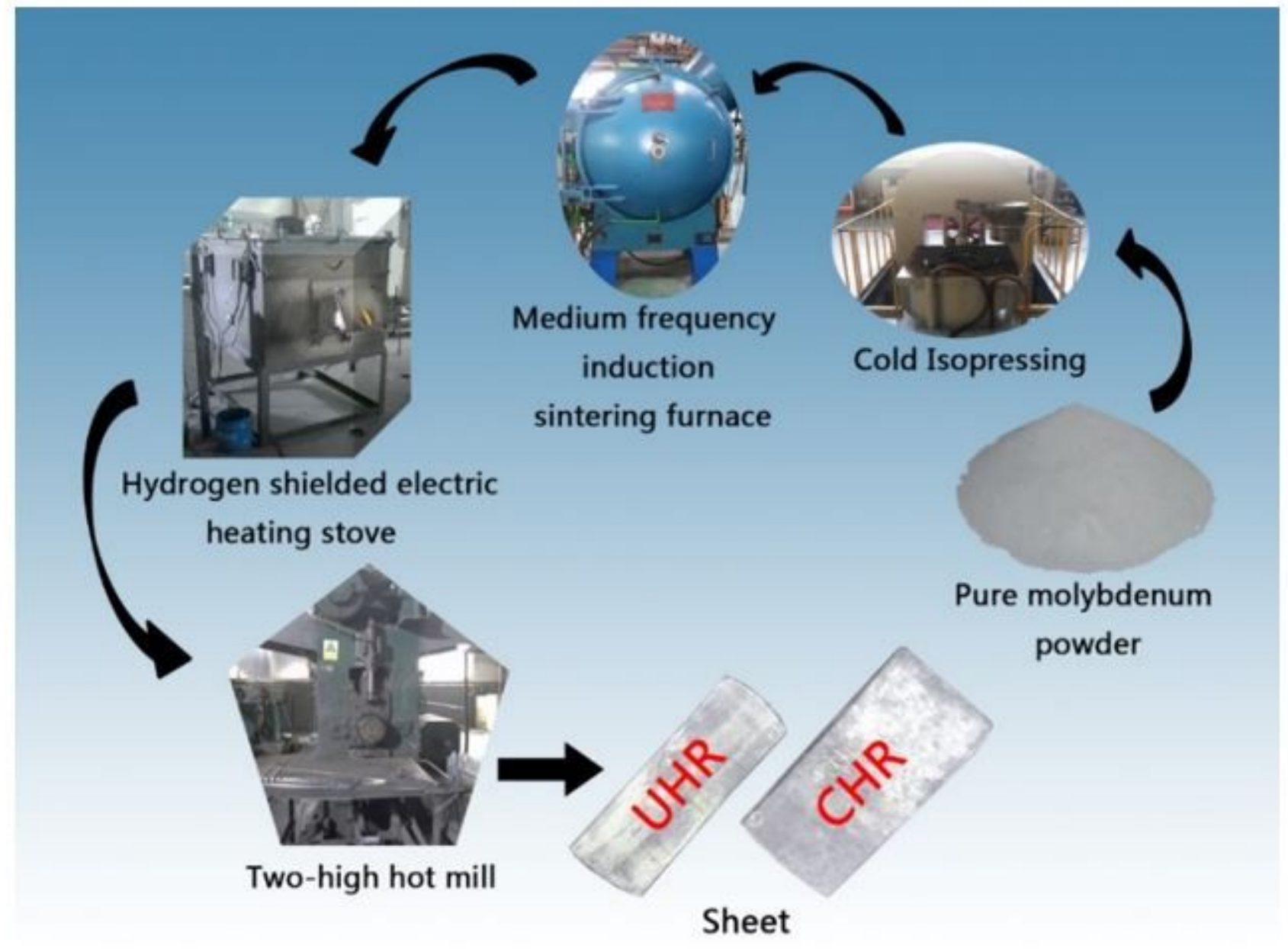

Figure 1

Preparation and rolling of molybdenum plate. 


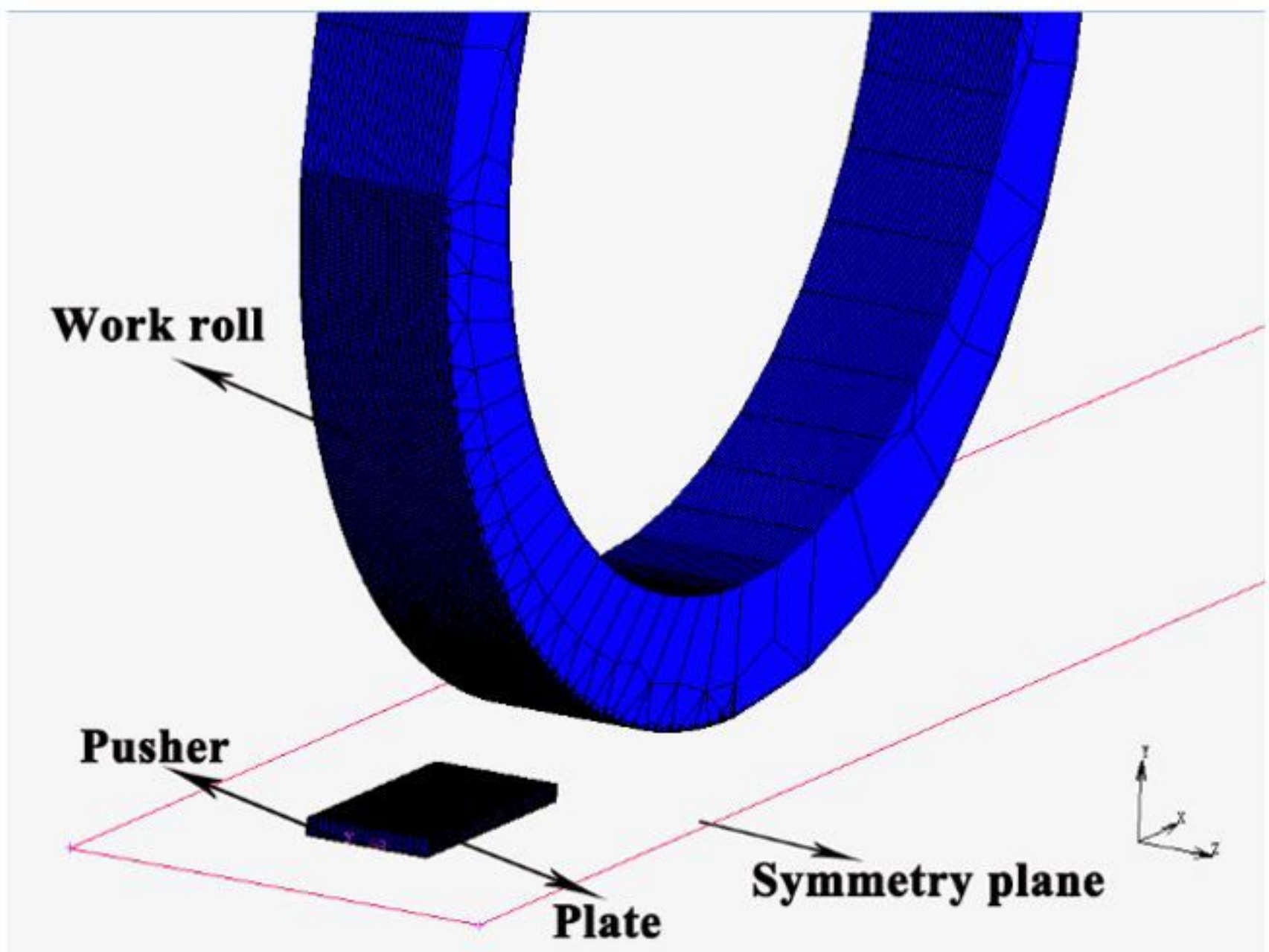

Figure 2

Finite element model.

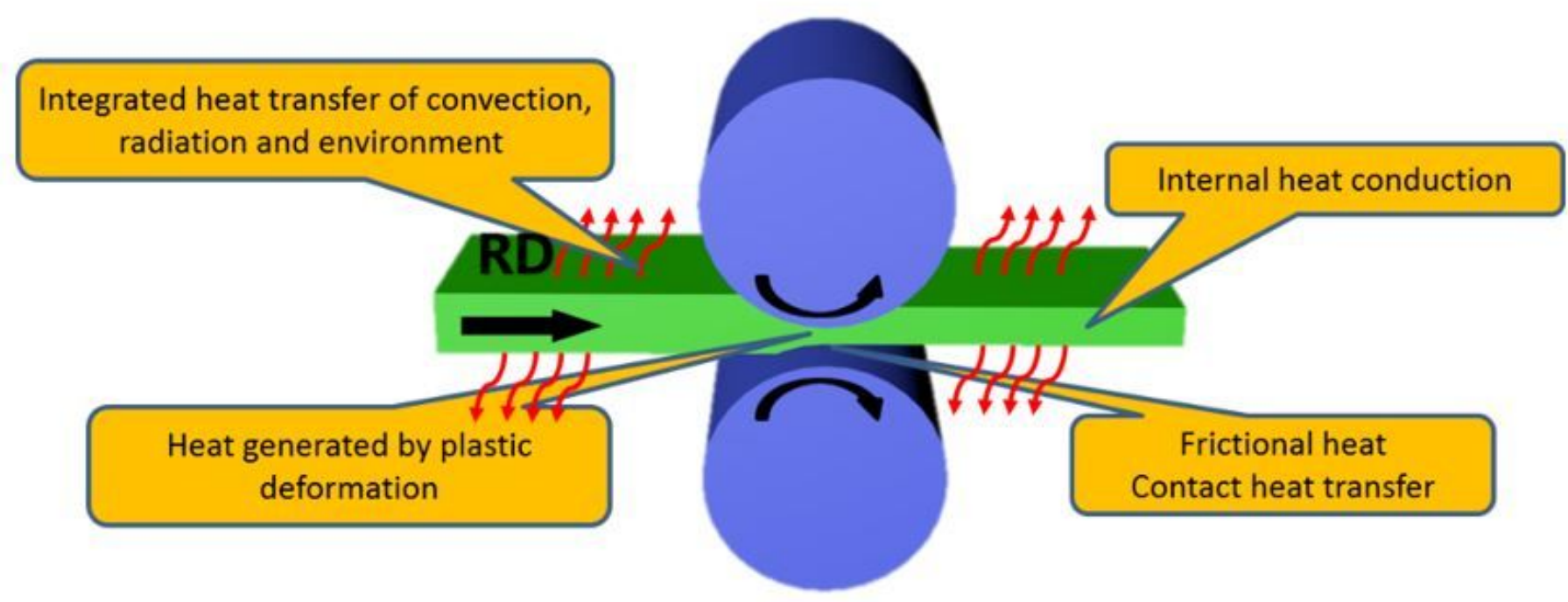

Figure 3 
Schematic diagram of boundary conditions during rolling process.

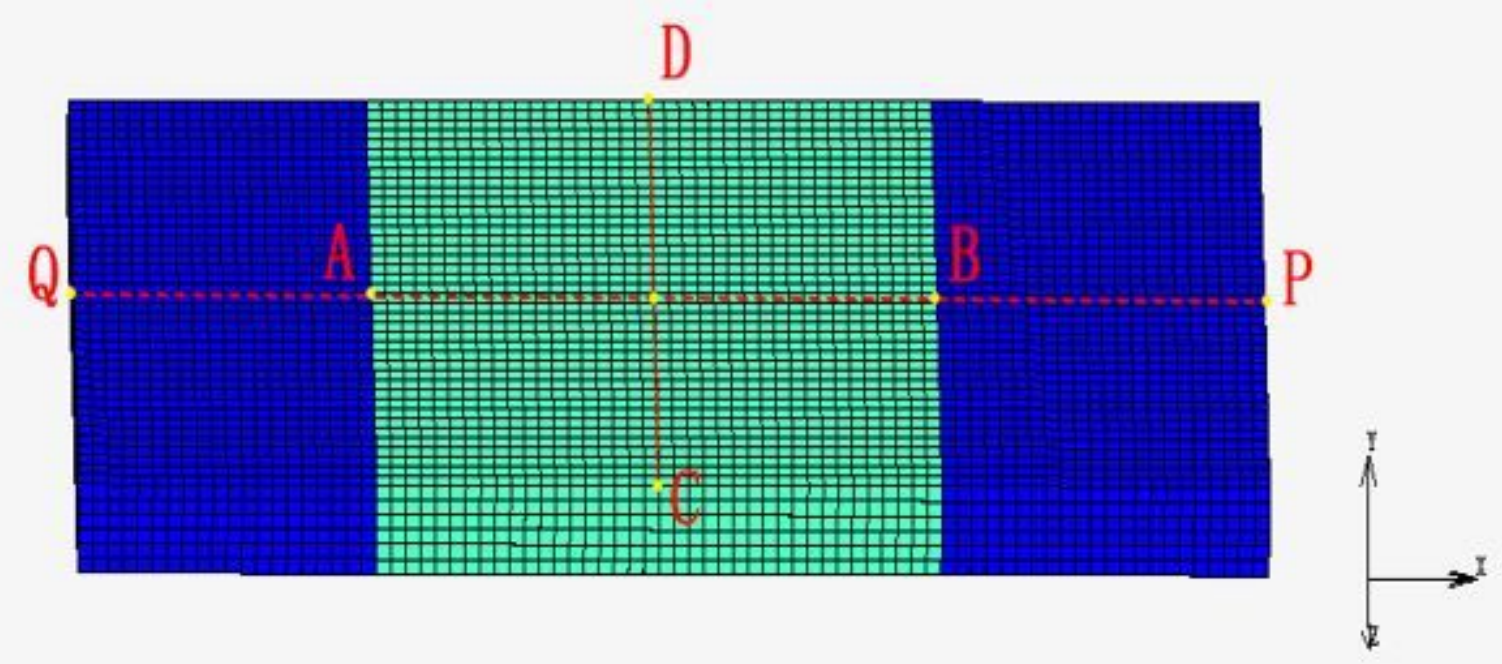

Figure 4

Display of the selected deformation area. 

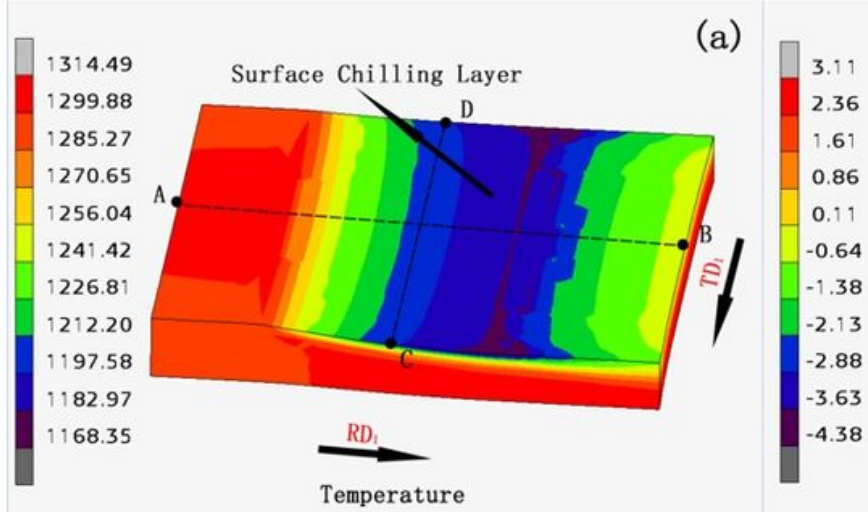

(b)

Temperature

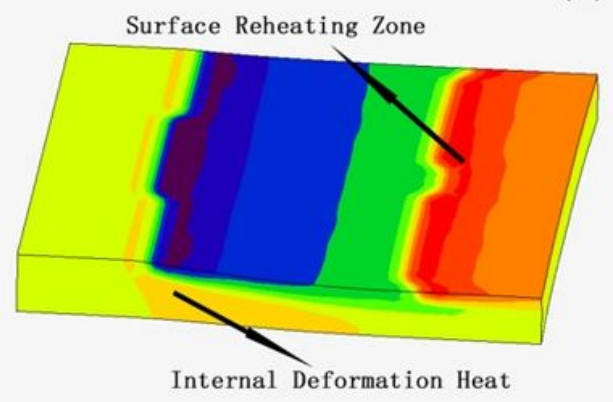

Temperature Increment

(c)

(d)
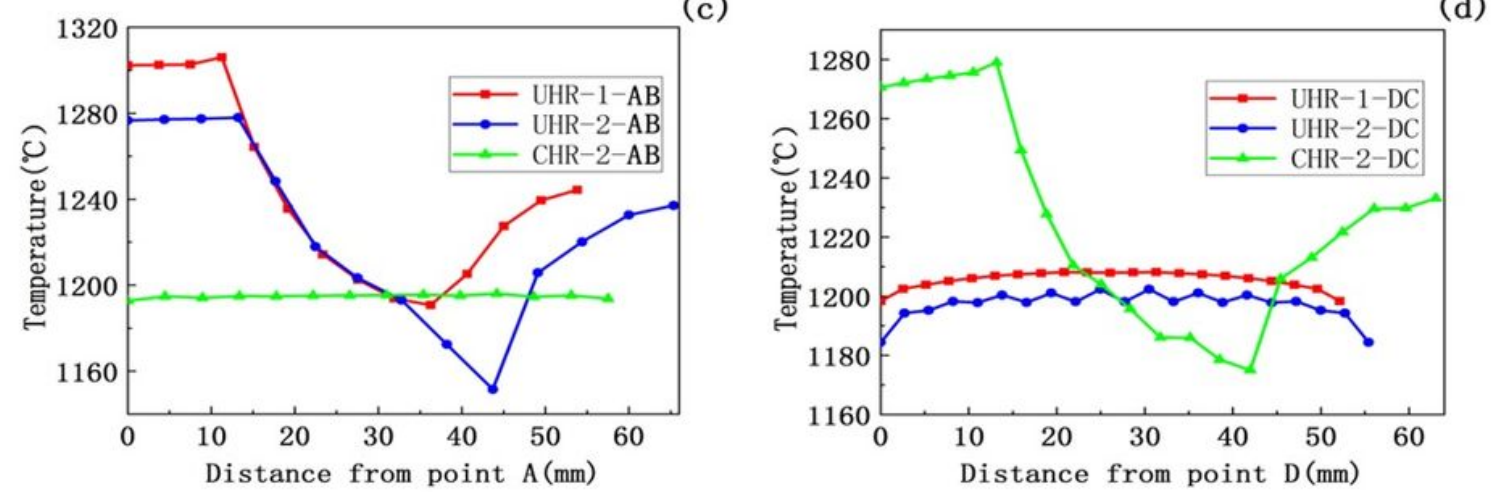

Figure 5

The first pass in the deformation zone: a temperature field, $b$ temperature increment contour (dT/dt); the temperature distributions of $c$ and $d$ are the lines of $A B$ and $D C$ under the two rolling conditions, respectively. 

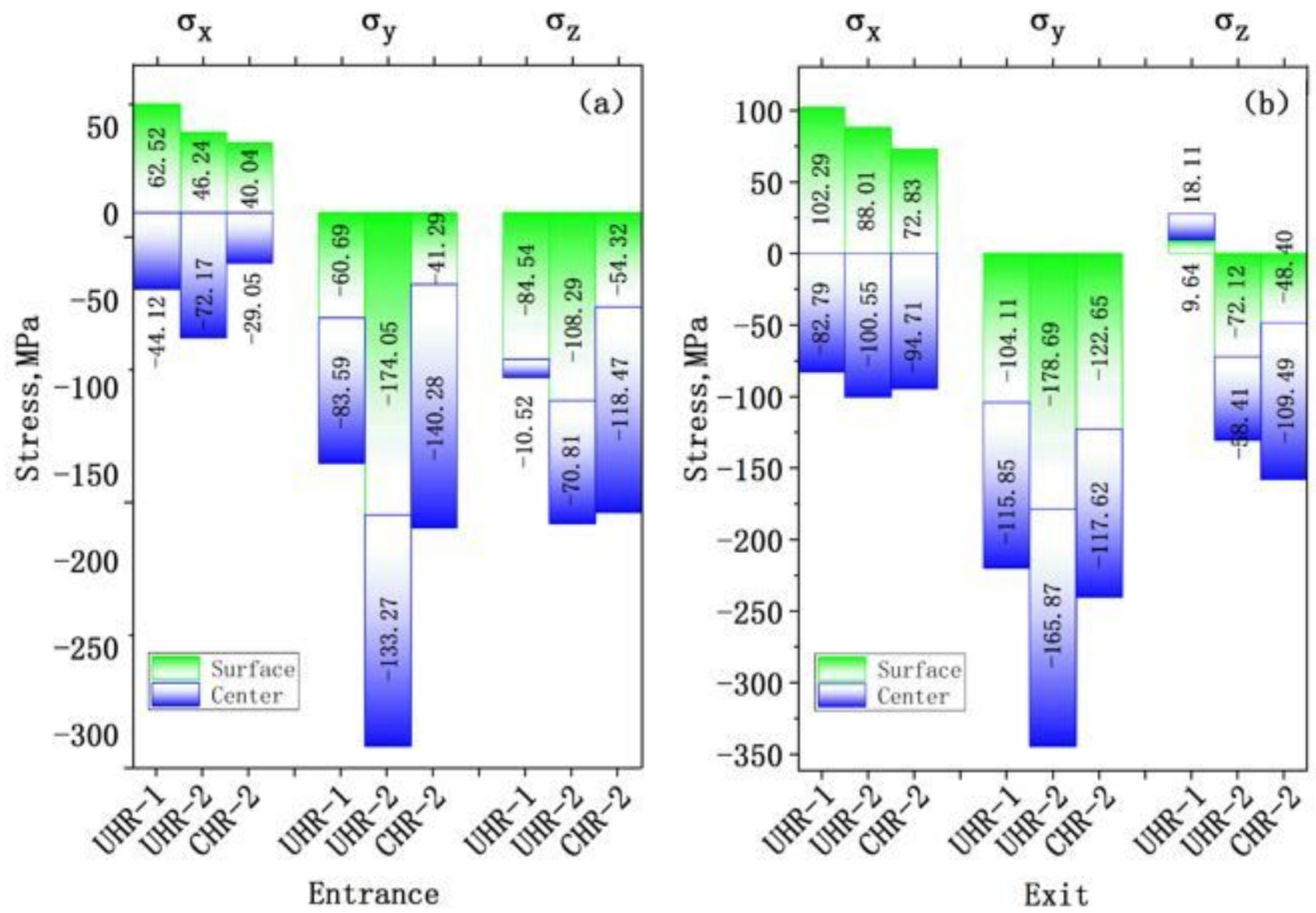

Figure 6

The distribution of additional stress at the entrance and exit of different passes under the conditions of UHR and $\mathrm{CHR}$. 

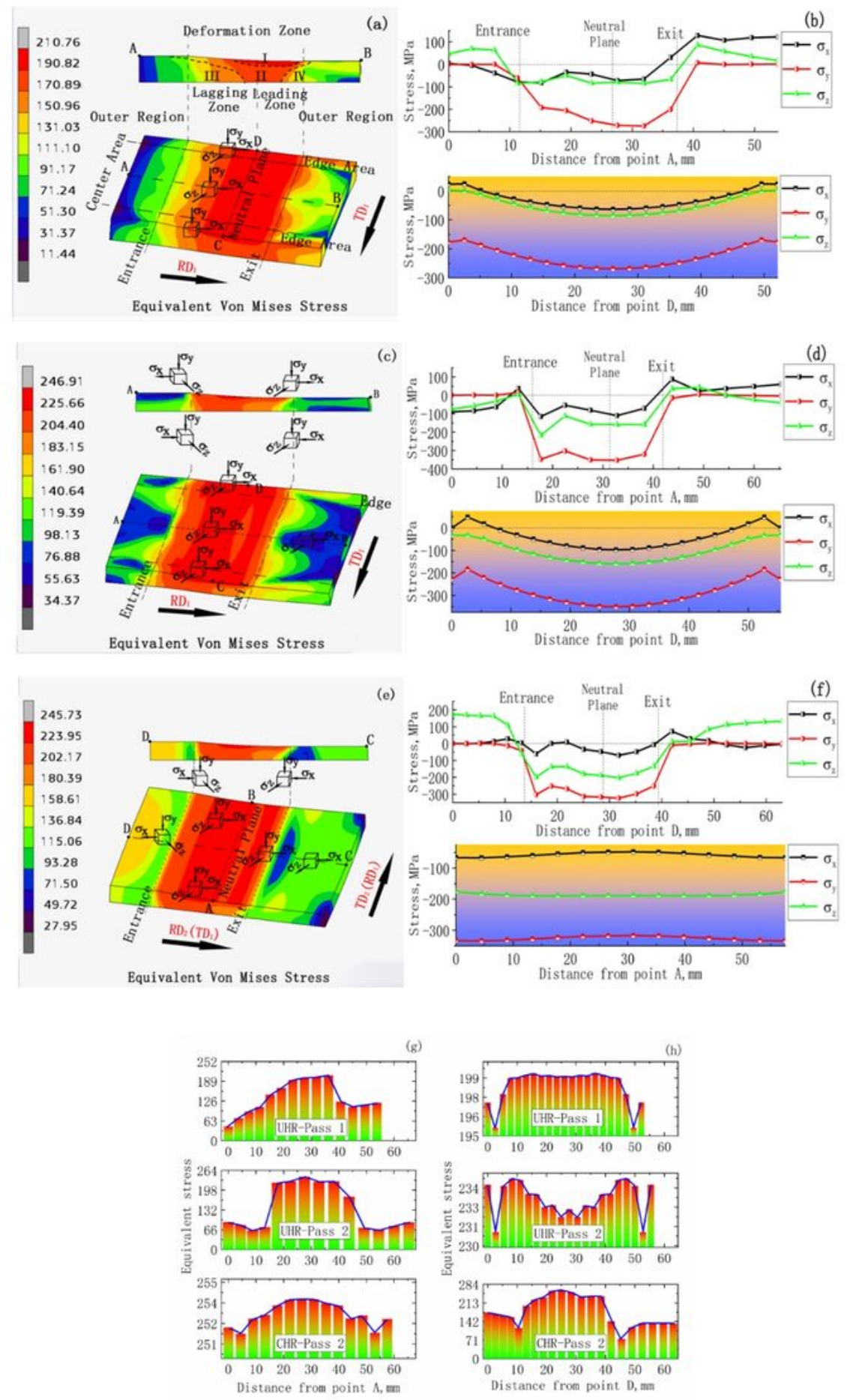

\section{Figure 7}

Equivalent stress distribution in rolling deformation zone a the first pass of UHR; $c$ the second pass of UHR; e the second pass of CHR; $b$, $d$, and $f$ are the additional stress distributions along $A B$ and $D C$ for each of the above passes; $g$ and $h$ are the equivalent stress curves of different passes along $A B$ and $D C$. 

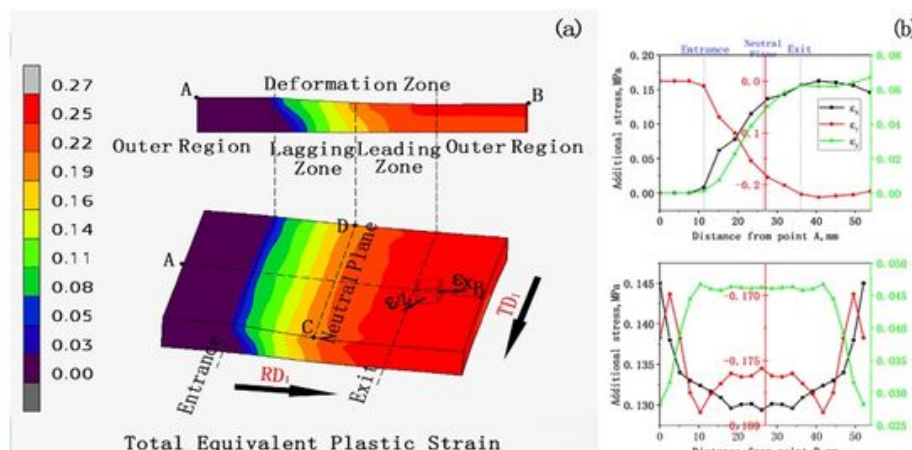

(b)

Total Equivalent Plastic Strain

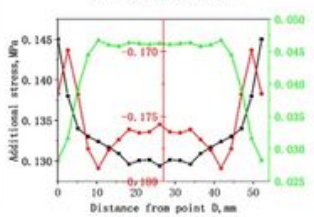

\begin{tabular}{|l}
0.65 \\
0.61 \\
0.57 \\
0.52 \\
0.48 \\
0.44 \\
0.40 \\
0.36 \\
0.31 \\
0.27 \\
0.23
\end{tabular}

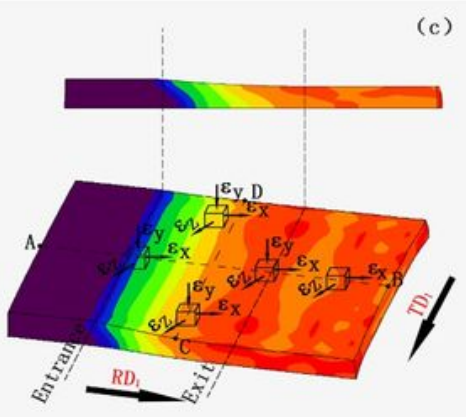

(c)

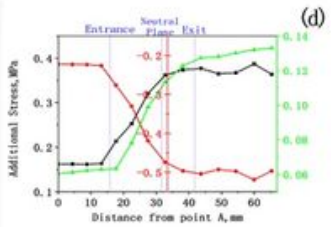

Total Equivalent Plastic Strain

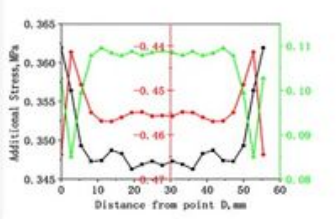

\begin{tabular}{|l|}
0.66 \\
0.62 \\
0.58 \\
0.54 \\
0.50 \\
0.46 \\
0.41 \\
0.37 \\
0.33 \\
0.29 \\
0.25
\end{tabular}

(e)
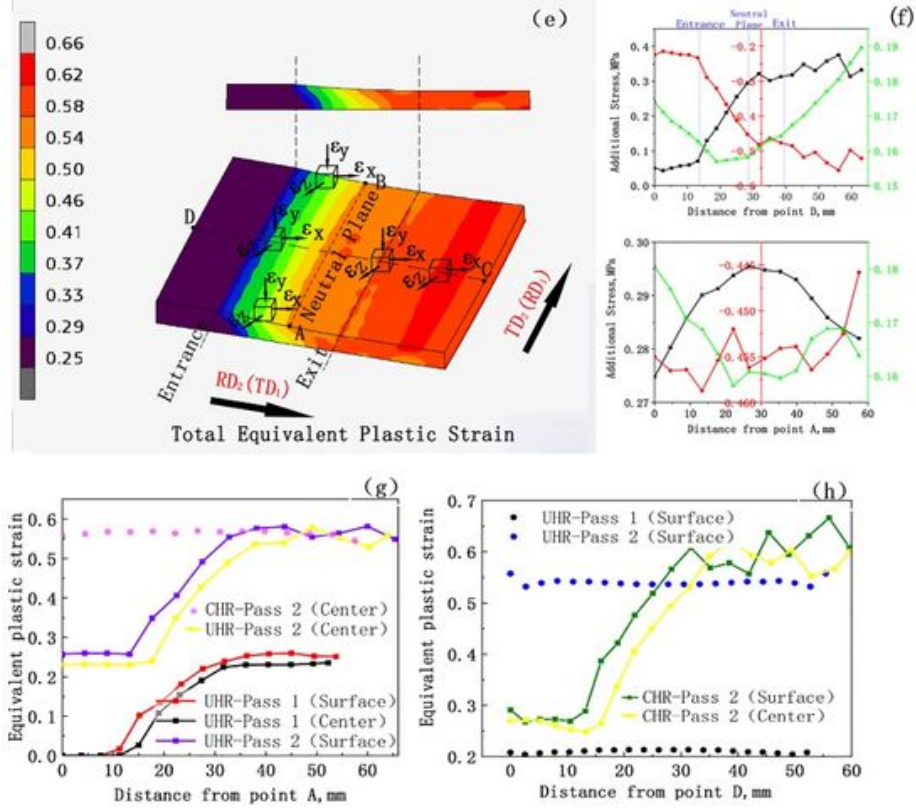

\section{Figure 8}

The contour maps of equivalent plastic strain in the rolling deformation zone: a the first pass; $c$ the second pass in UHR; $e$ the second pass in CHR; $b, d$ and $f$ are the distributions of additional strain along lines of $A B$ and $D C$ in each pass respectively; $g$ and $h$ are the evolution of equivalent strain along lines of $A B$ and $D C$, respectively. 

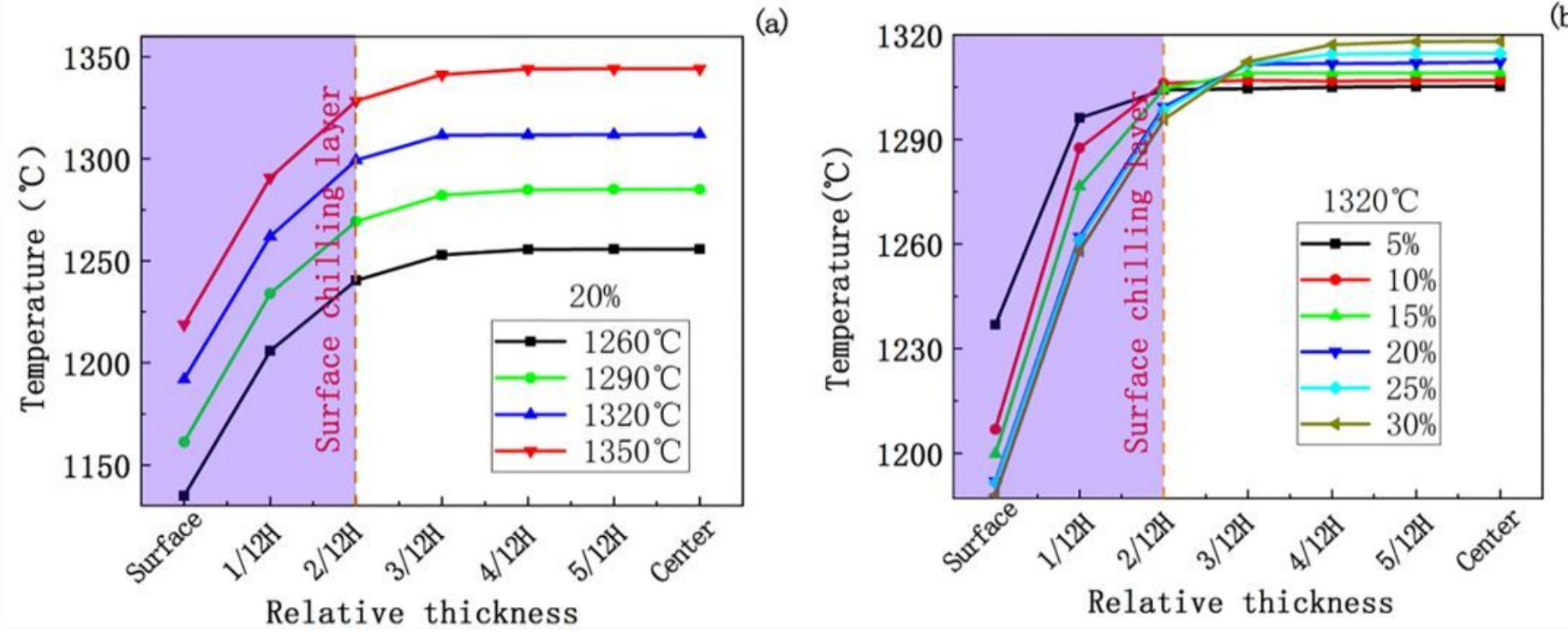

Figure 9

Effects of a initial rolling temperature and $b$ reduction on temperature distribution along thickness direction at the exit.

(a)
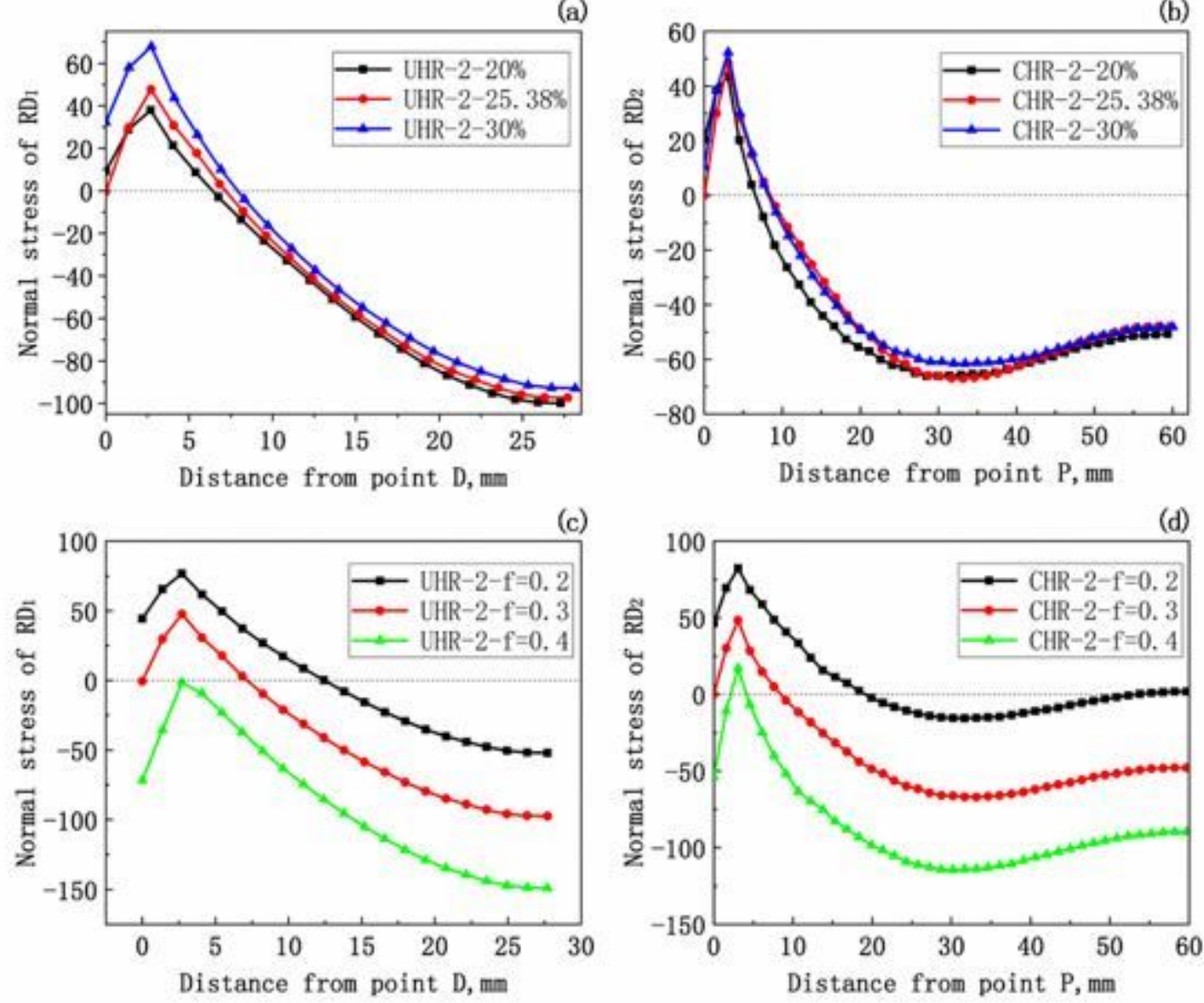

Figure 10 
The effect of different parameters on the distribution of $x$-direction tensile stress along the width direction on the neutral surface under the two rolling modes: $a$ and $b$ reduction; $c$ and $d$ friction coefficient.
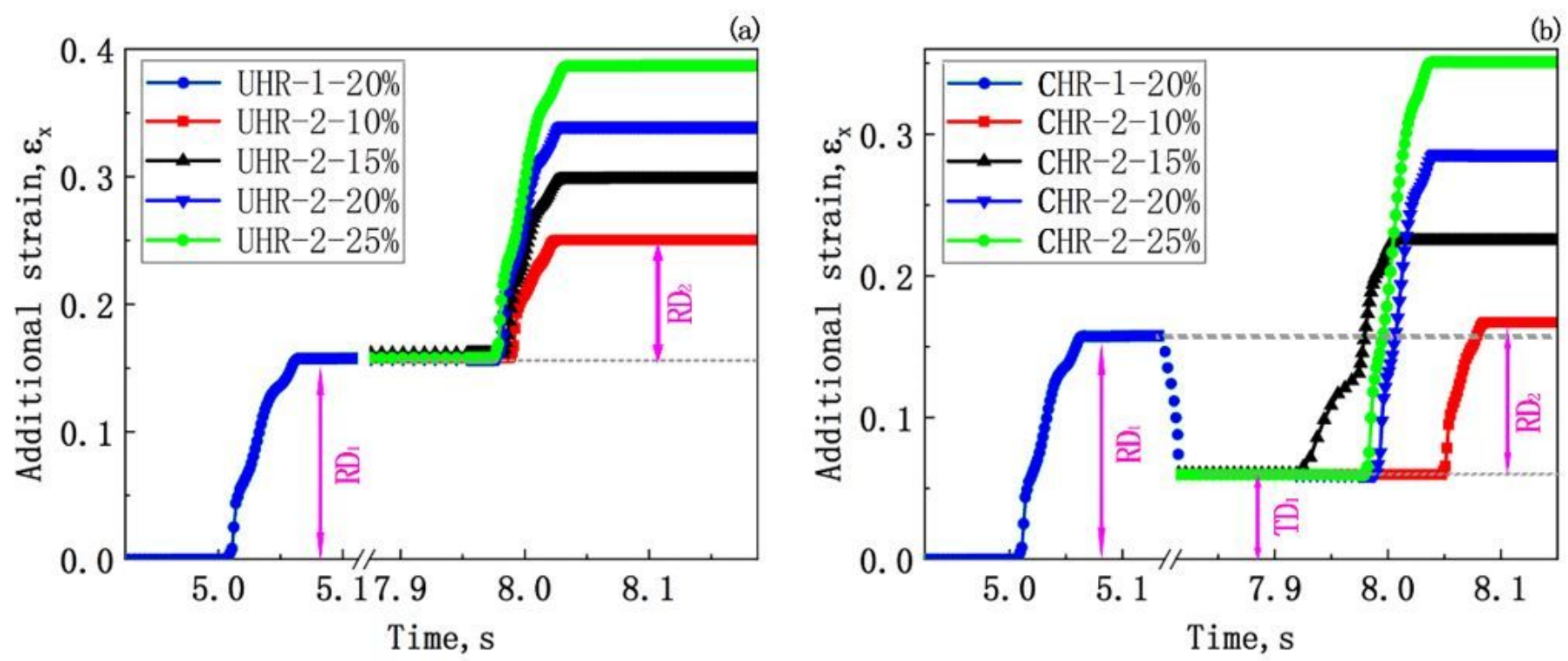

Figure 11

Effect of different reductions on plastic strain at a point on the plate surface along $x$-direction: $a$ UHR; $b$ $\mathrm{CHR}$ 


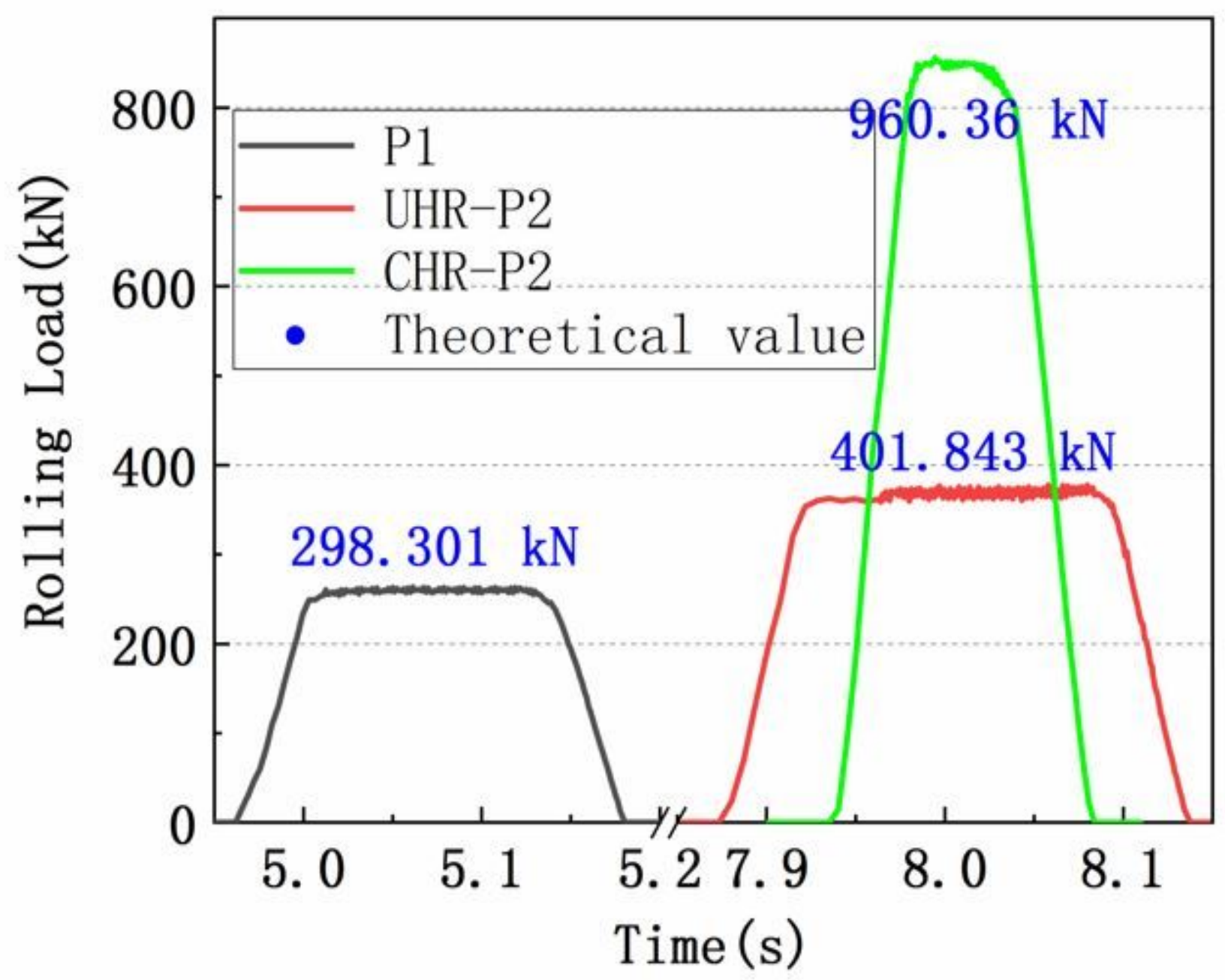

Figure 12

Comparison of theoretical rolling force and simulated rolling force under UHR and CHR. 